\title{
COMPARACION ENTRE DOS ECOSISTEMAS TROPOANDINOS: LA PUNA CHILENA Y EL PARAMO ECUATORIANO
}

\author{
COMPARISION BETWEEN TWO TROPOANDEAN ECOSYSTEMS: \\ THE CHILEAN "PUNA" AND THE ECUADORIAN "PARAMO"
}

\author{
VICTOR QUINTANILLA P.
}

Departamento de Geografía Universidad de Chile

\begin{abstract}
This survey is a preliminary, comparative study of the phyto-ecologic features of two great types of ecosystems of the Andes mountain range.

It deals with the Chilean "puna" in northern Chile (volcanic region of the Pallachatas, Is/uga, Guallatire, and Colorado hills all of which are over $6.000 \mathrm{~m}$ above sea levell and the Ecuador paramos (volcanic regions of Cotopaxi and Rumiñahui in the west and the central range of the country).

Numerous samples were collected in the field according to the Canfield lineal method and the Braun-Blanquet one. The data were used to establish the frequency percentage, prevalence, covering, and importance index of shrubs and herbaceous species representative of vegetal formations. These groups were found on the vegetal range floor of the "puna" and "paramo" (over $3.000 \mathrm{~m}$ above sea level). They proved to have a very similar composition in gender and family but they are different at the level of species. There were only two plants. Stipa-ichu and dense Azorella which presented a high index of common representativeness in both ecosystems.

This botanical variety is mainly due to the different ways that the definitive ecological factors affect the development of herbaceous species. In the "paramo", there are some factors that help the development of extensive shrub and herbaceous communities, such as, favourable exposition, high atmopheric humidity, and high rainfall. All of these help provide a high degree of cover and a dense physiognomy. Meanwhile, in the "puna" there are some factors, such as the high atmospheric dryness, low rainfall, and the existence of unfertile soils which are appropriate for the development of plants adapted to dryness, cold, and wind. They contribute to the formation of open intermediate altitude shrubs and rangelands lower in altitude than in the "paramo".

The comparative tables and the vegetal profiles show the predominance of herbaceous species in the high mountain communities and the extense altitudinal distribution of these. Some are living close to the lower limit of the eternal snows of the volcanoes.

Specific, morphological, and physiological functions of the plants would explain the great ecologic adaptability of these species to exist in mountains over $5.000 \mathrm{~m}$ in altitude.
\end{abstract}

\section{ANTECEDENTES Y OBJETIVOS}

La intención de este trabajo preliminar es entregar por el momento, una visión general del ordenamiento de los tipos vegetales, de la composición florística y de la ecología, en dos ambientes biogeográficos de los Andes tropicales. En ellos se denotan semejanzas y diferencias 
de formas de vida, particularmente, de modo global se comprueba que estos ecosistemas poseen una ecologia fundamentalmente distinta, a pesar de localizarse en un rango altitudinal muy similar. De acuerdo con el enfoque propuesto por TrOLL (1958) y aplicado posteriormente por otros autores como Lauer, Cuatrecasas, Acosta Solis, etc., el término tropoandino se refiere al sector tropical altoandino de América Latina. Esta gran área tropandina es exclusiva, y su ecologia y vegetación es distinta de las otras regiones tropicales de África, Asia y de las islas tropicales del Pacífico. Ello se debe principalmente a la gran influencia orográfica y altitudinal de los Andes.

La ecología y flora de los sistemas montañosos no posee ambientes homólogos en las cordilleras andinas de América del Sur, a pesar de las características ambientales similares que presentan (CzJAKA, 1968).

En varias regiones a lo largo de toda su extensión, la cordillera andina se bifurca en grandes brazos montañosos encerrando regiones elevadas situadas por sobre los 3.000 metros y que son objeto de un permanente interés científico. Un piso regionalmente denominado "páramo" se extiende en el norte de América del Sur hasta alrededor de los $14^{\circ} \circ 15^{\circ}$ Sur. A continuación de esta latitud y hasta alrededor de los $27^{\circ}$ lat. Sur, la intrincada orografía andina da paso a nuevos sistemas elevados que por sus características peculiares son regionalmente conocidos como "puna" o "altiplano" (Fig. 1 y 2). El término "puna" es de origen quechua y significa terreno

\section{LOCALIZACION DE LAS ZONAS DE ESTUDIO EN LA PUNA CHILENA.( 䀚)}

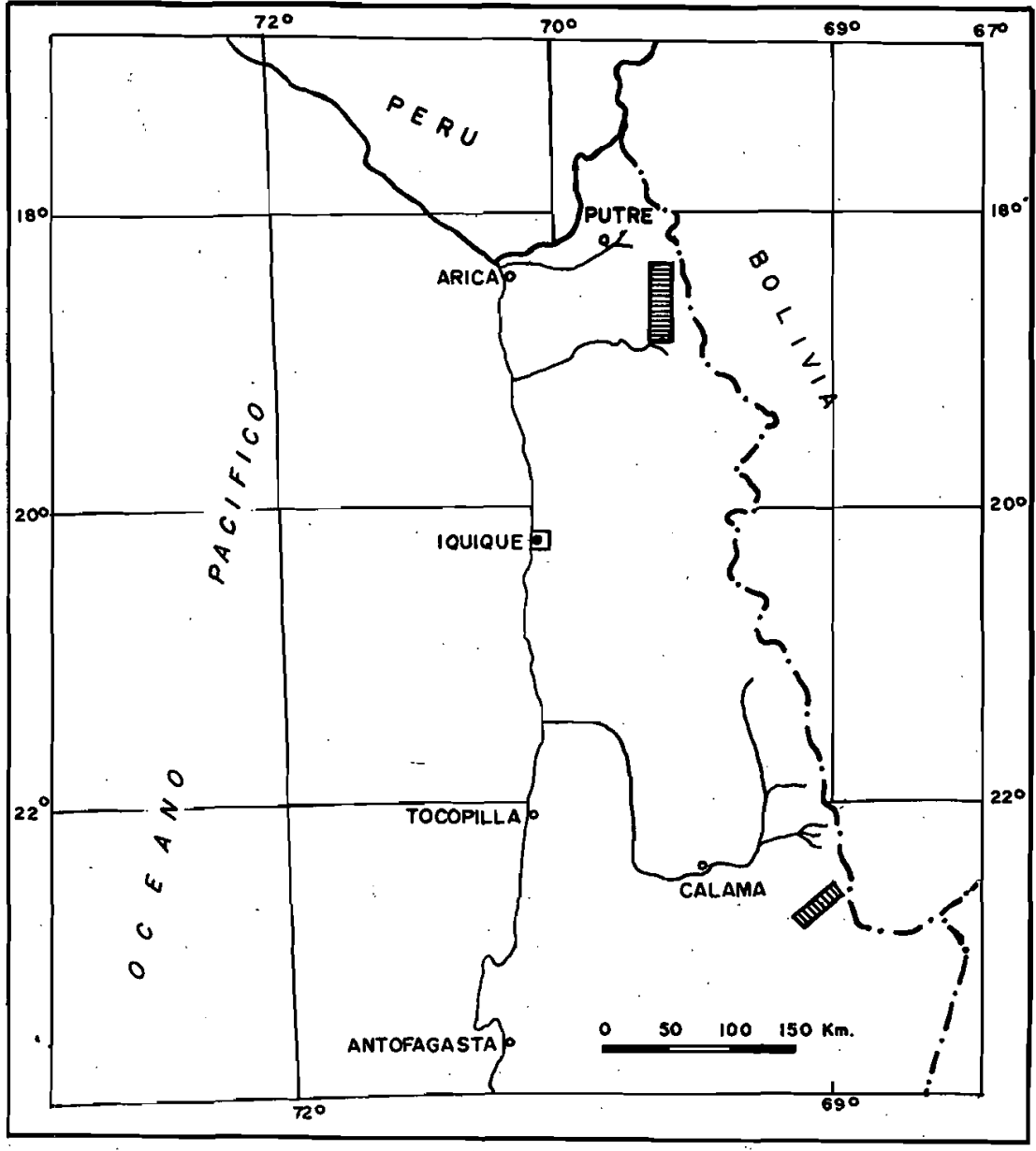

CARTOBRAFIA: MA.MORAC. 


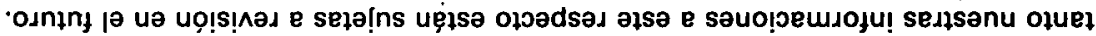

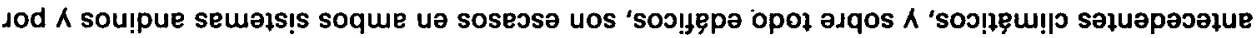

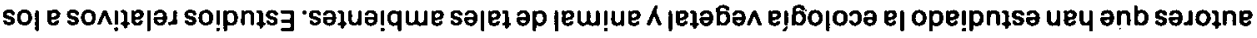

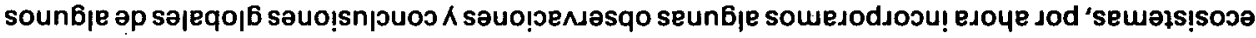

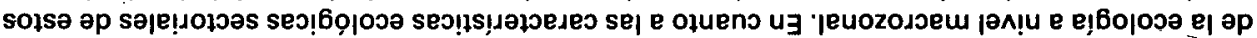

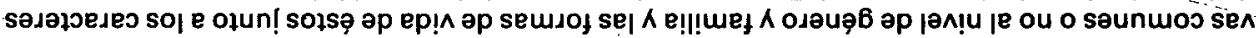

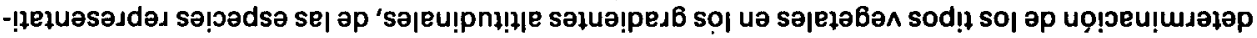
e| 's o!pnłsə odtsənu әp jed! ou!

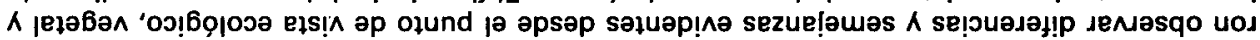

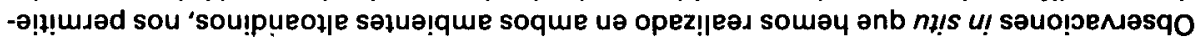

'soue!

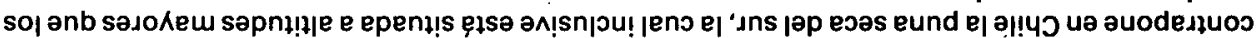

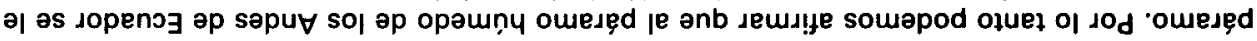

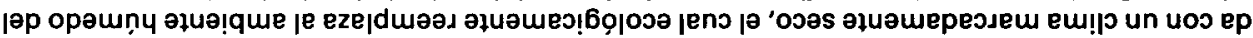

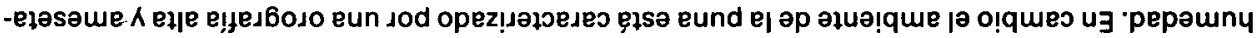

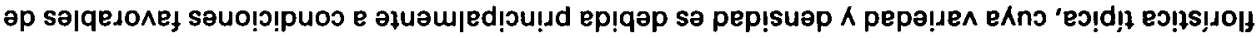

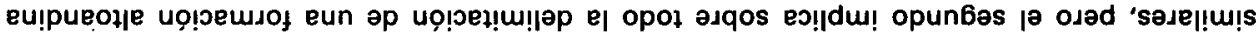
seo!

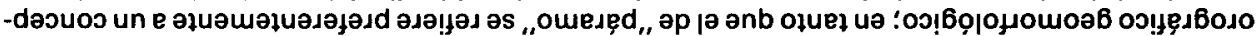

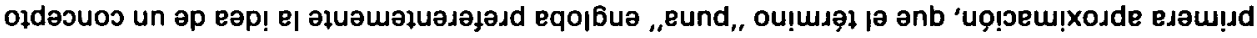

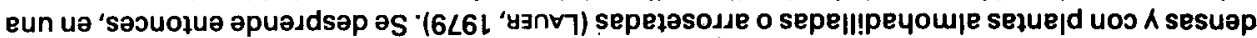

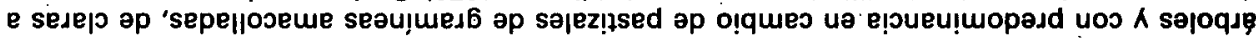

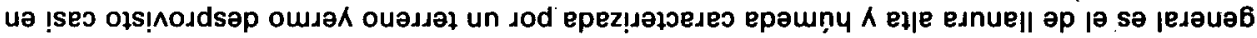

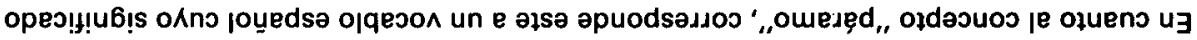

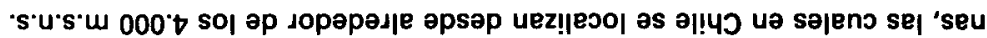

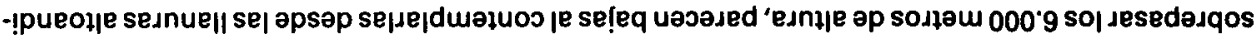

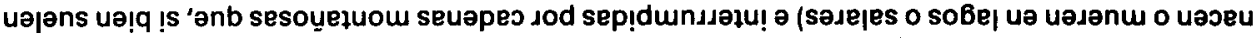

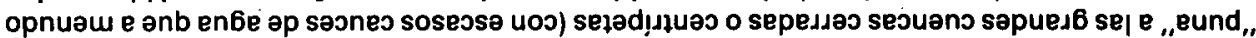

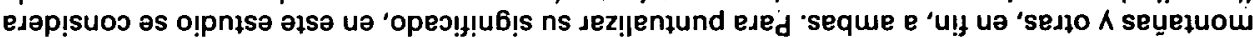

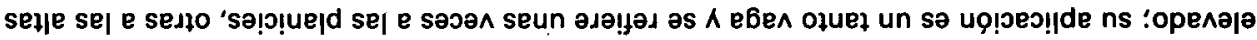

\section{$z \cdot 6 ! y$}

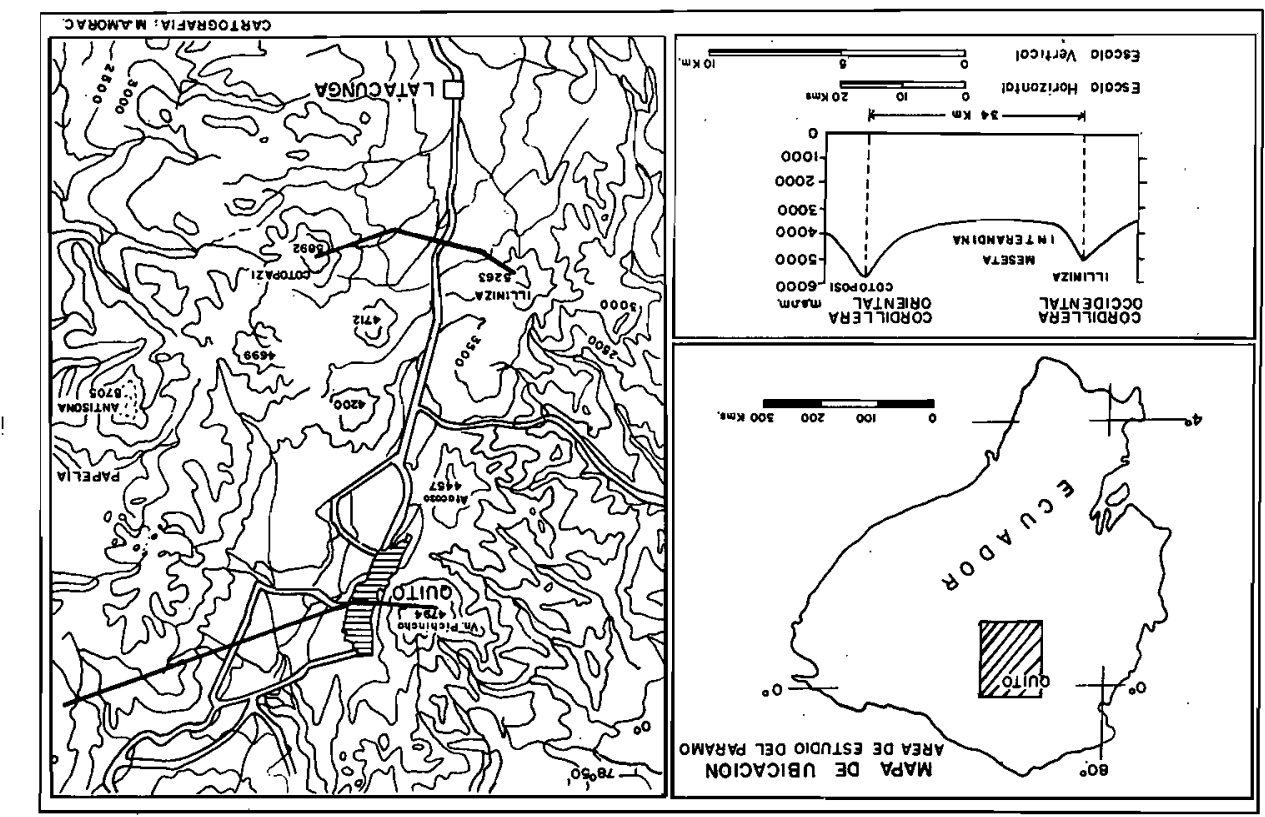

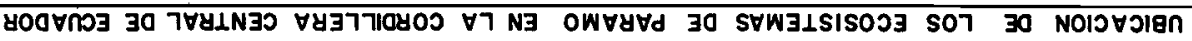


páramos de la cordillera oriental del Ecuador (Parque Nacional del volcán Cotopaxi $5.807 \mathrm{~m}$, volcán Rumiñahui $4.712 \mathrm{~m}$ ), y en la puna chilena indistintamente se efectuaron entre los meses de marzo a julio durante los años 1975, 1977, 1979 y 1980 . El trabajo de campo se centró preferentemente en el Parque Nacional del Lauca (regiones de Parinacota, Chungará, volcán Guallatiri 6060 $m$ y Salar de Surire) y el sector septentrional del Parque Nacional Isluga; todos en la $I^{\mathbf{\theta}}$ Región. También trabajamos en los interiores altoandinos de la localidad de San Pedro de Atacama en los cañones de los rios Vilama, Guatín, Puripica y en Cerro Colorado $\left(5.742 \mathrm{~m}\right.$ ) en la $11^{\mathrm{a}}$ Región. Resultados de parte de estos estudios de campo, tanto en la puna como en el páramo, los hemos adelantado en publicaciones anteriores (QUINTANILLA, 1976-1977 y 1983). Para ambas regiones hemos realizado algunos análisis estadístico matemáticos con el objeto de comparar el índice de similitud de especies de las comunidades representativas y su índice de valor de importancia en los dos grandes ecosistemas, cuyo proceso en detalle esperamos entregar en una comunicación próxima.

Como la expresión de estas regiones es notable y considerando que en los ambientes de los altos Andes predominan formas de vida arbustivas y herbáceas, así como la rigurosidad del clima que obliga a efectuar breves campañas de terreno, el tipo de muestreo preferentemente empleado fue el denominado de "intersección lineal" (Línea de Canfield con ciertas modificaciones). Consiste ésta en inventariar y evaluar diversos parámetros estructurales o funcionales de todos y cada uno de los individuos que concurren a lo largo de una línea recta de extensión variable (Fig. 3). También a veces utilizamos el conocido método de censos de Braun-Blanquet.

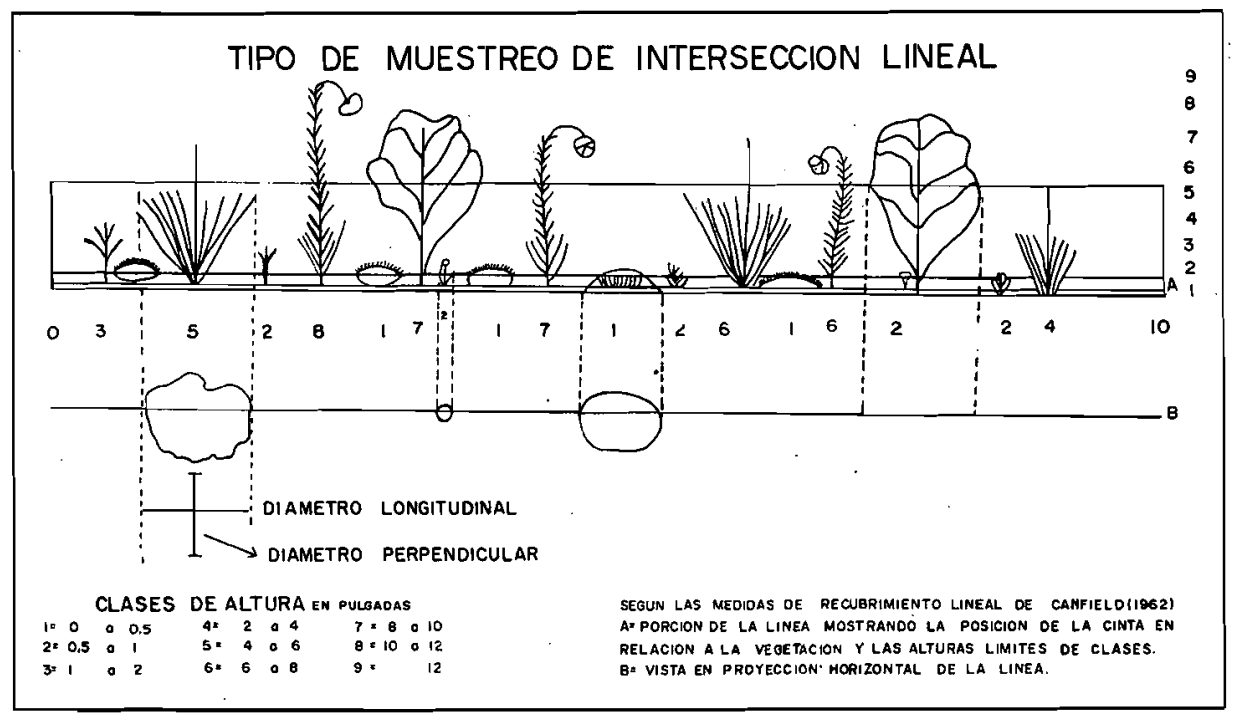

Fig. 3

En la cordillera ecuatoriana se realizaron 63 muestreos con la colaboración de los becarios del Curso Internacional de Biogeografía Aplicada efectuado durante 1982 en el Centro Panamericano de Estudios e Investigaciones Geográficas (CEPEIGE) de Quito y en los ecosistemas chilenos efectuamos un total de 60 muestreos. La superficie del área de relevamiento de los muestreos de Braun-Blanquet fue de $10 \mathrm{~m}^{2}$ en las comunidades de gramineas y de $20 \mathrm{~m}^{2}$ en las arbustivas. En cuanto a la extensión de muestreo lineal depende ella de las caracteristicas de la diversidad de especies y de la estructura de la comunidad analizada. Con el objeto de alcanzar una buena representatividad se realizó un análisis del tipo "área mínima" es decir, se determinó la extensión de la línea dentro de la cual se encuentra representada la mayoria de las especies, o al menos la mayoria de las especies más representivas de la comunidad. Como se aprecia en la Fig. 4, a medida que aumenta la extensión de la línea, se encuentran nuevas especies; pero a partir de cierta longitud la curva sufre una inflexión y el número de especies nuevas que aparecen decrece totalmente, o sea, a partir de esta distancia ya no encontramos nuevas especies o las que aparecen generalmente son muy dispersas y desempeñan un rol "secundario" desde el punto de vista estructural y funcional de la comunidad vegetal. 


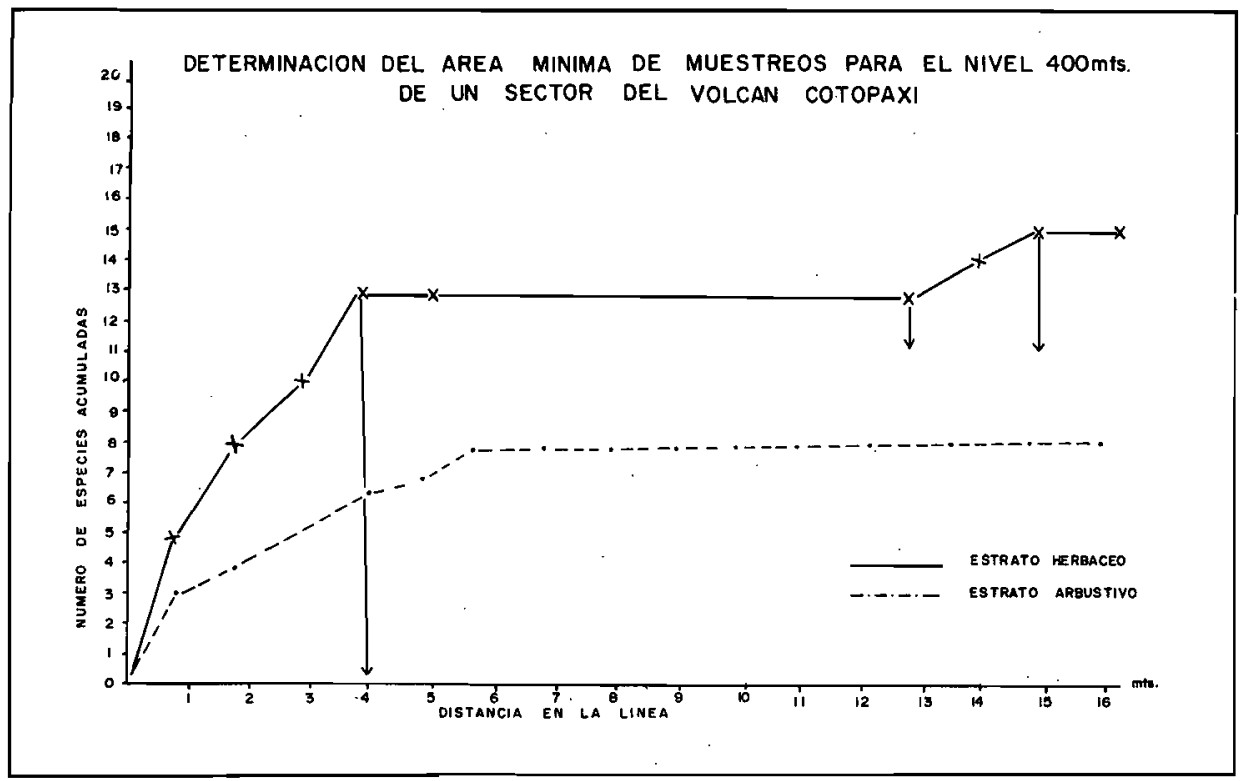

Fig. 4

Una vez establecidas y delimitadas las líneas de muestreo se procedió a la cuantificación y análisis de los distintos parámetros a considerar en la comunidad.

Después de establecer la lista florística preliminar se realizó el análisis de la estructura de las comunidades. Para esto se estimó la abundancia absoluta de cada especie, cuantificando el número de veces que esta fue interceptada a lo largo de la línea (AXE $=\mathbf{N}^{\circ}$ total de especies). La abundancia relativa se calculó expresando el porcentaje de una especie con respecto a la sumatoria de las abundancias absolutas de todas las especies

$$
\left(A R X=\frac{A X}{A T} \times 100\right)
$$

Con respecto a la dominancia absoluta, se consideró el área de cobertura de follaje de las plantas para cada especie. Se calculó tomando como base el diámetro de cobertura (diámetro longitudinal más diámetro perpendicular entre dos plantas (Ver Fig. 3). A partir de esta medida se calculó el área de cobertura en $\mathrm{cm}^{2}$ para cada individuo y en promedio para la especie. La dominancia relativa se expresó como el porcentaje de cobertura de una especie con relación a la sumatoria de las coberturas de todas las especies

$$
\text { (DMRX } \left.=\frac{\text { DMX }}{\text { DMT }} \times 100\right) \text {. }
$$

En cuanto a la frecuencia absoluta se midió como el porcentaje de líneas en que aparece una especie y la frecuencia relativa se expresó como el porcentaje de una especie con respecto a la sumatoria de las frecuencias de todas las especies

$$
\left(F R X=\frac{F X}{F T} \times 100\right) .
$$

El índice de valor de importancia (I.V.I.) evalúa la importancia (estructural o funcional) de las diferentes especies en la comunidad y sitio de muestreo y resulta de la sumatoria de los respectivos valores de frecuencia, abundancia dominancia relativa de cada especie (I.V.I. $=A R X+F R X+$ DMRX). Luego, el I.V.I. de una especie es I.V.I. X = (ARX + FRX + DMRX)/3.

Para calcular al coeficiente de similitud o afinidad florística de las diversas comunidades se utilizó el método llamado "análisis diferencial de Cekanowski" el cual se basa en el cálculo del coeficiente de comunidad florística que, para cada inventario, representa el número de especies que tiene en común con cada uno de los demás:

$$
\mathrm{C}=\frac{\mathrm{n} \times 100}{\mathrm{~N}}
$$

en donde $A$ y $B$ son dos comunidades vegetales

$n$ el $N^{\circ}$ de especies comunes a las comunidades $A$ y $B$.

$\mathrm{N}$ el $\mathrm{N}^{\circ}$ total de especies presentes en los dos inventarios.

Con los datos obtenidos se construye una matriz de doble entrada en la cual cada línea y cada 
columna representan en este caso niveles o estratos altitudinales diferentes. Ello permite analizar las áreas de estudio y comparar la similitud en cada uno de los estratos altitudinales.

La identificación de las colectas de la puna fue realizada en 1978 y 1979 en el Depto. de Biología de la Universidad de Chile sede Antofagasta y en parte ha sido actualizada por estudios publicados posteriormente, como por ejemplo a través de trabajos de VILLAGrán et a/ (1981). Las plantas colectadas en el páramo, fueron clasificadas por el Depto. de Botánica de la Universidad Central del Ecuador en Quito en el año 1982 y particularmente por el Profesor H. Baslev.

\section{LOS ANTECEDENTES ECOLOGICOS PRINCIPALES}

La gran extensión latitudinal de la cordillera andina determina que esté en contacto con zonas de influencias microclimáticas muy diferentes. A esta diversidad de condiciones se agrega y superpone además la configuración de pisos bioclimáticos altitudinales que favorecen el desarrollo de ecosistemas muy variados y complejos. Para la vida vegetativa y faunistica de estos ambientes, la humedad desempeña un rol preponderante. De acuerdo a este factor varios autores como TroLL (1968), MANN (1966) y LAUER (1979), entre otros, han determinado diversas zonas de vida en esta cadena andina. En los Andes tropicales septentrionales de América del Sur hasta más o menos los $12^{\circ}$ lat. Sur, el hábitat está caracterizado por el clima ecuatorial que le otorga un total elevado de precipitaciones acompañadas por temperaturas relativamente altas, hasta alrededor de los 3.000 m.s.n.m. Entre los $12^{\circ}$ y los $26^{\circ}$ Sur, predominan vientos alisios portadores de masas atmosféricas más o menos saturadas por la humedad que han absorbido sobre la cuenta amazónica. En este sector de la puna y altiplano, se invierte por consiguiente la gradiente de humedad caracteristica de los Andes septentrionales con mayores precipitaciones al oriente y mínimas hacia el occidente de la cordillera. Por otra parte la presencia o ausencia de vientos y de la radiación, actúan como factores decisivos en el régimen térmico de los ambientes altoandinos. Así la radiación es el factor preponderante en la marcha anual y diaria de la temperatura y del clima en general, en los ecosistemas de la puna chilena. A causa de la disminución de la presión atmosférica, ya a una altura de 4.000 a 5.000 metros, los rayos solares deben penetrar solamente un poco más de la mitad de la baja atmósfera: esta parte de la atmósfera se destaca también por su pureza y la ausencia casi total de vapor de agua, hecho que no ocurre en el páramo ecuatorial. La menor densidad del aire y su mayor pureza producen, asi mismo una sensible disminución en el efecto de invernáculo de la atmósfera, por lo cual una mayor cantidad de radiación calórica efectiva que emite la superficie terrestre escapa a las capas de la atmósfera. Naturalmente ello trae consecuencias inmediatas en el régimen térmico: un intenso calentamiento de la superficie del suelo en horas del día y un enfriamiento igualmente intenso durante la noche, ambos procesos favorecidos además por la mala conductibilidad térmica del suelo arenoso en los altiplanos y por el gran contraste que se experimenta entre sol y sombra. En las regiones de la puna se registran amplitudes térmicas diarias entre $16^{\circ}$ y $20^{\circ} \mathrm{C}$, una de las mayores en el globo (MANN, 1966). En los páramos ecuatorianos estas amplitudes son entre $5^{\circ}$ y $9^{\circ} \mathrm{C}$ en la cordillera central. Contrastan también los violentos descensos de temperatura que pueden exceder los $20^{\circ} \mathrm{C} 24 \mathrm{hrs}$ en el medio puneño. Bajo tales condiciones de noches gélidas y dias tibios, se determinan rigurosos periodos de actividad para las plantas y particularmente para los animales poiquilotermos quienes deben aprovechar los momentos térmicos favorables para el desarrollo de su vida. Por otra parte la humedad atmosférica aqui es muy baja, no alcanzando al $50 \%$.

Por la influencia de la cantidad de lluvia que se registra en los ambientes tropoandinos MANN (1966) distingue cuatro tipos de hábitats en ellos: $1^{\circ}$ ) el Páramo con más de $1.000 \mathrm{~mm}$ de lluvia anual y un excedente minimo sobre la evapotranspiración de $750 \mathrm{~mm}$; este páramo se extiende desde $10^{\circ} \mathrm{N}$ a $18^{\circ} \mathrm{S}$ y luego al sur de la latitud de $40^{\circ}$ en forma de páramo frío. $2^{\circ}$ ) Puna húmeda con lluvias entre 500 y $1.000 \mathrm{~mm}$ que permiten un excedente de 250 a $750 \mathrm{~mm}$ de precipitación sobre la demanda de la evaporación y evapotranspiración; este hábitat se inicia en la latitud $10^{\circ} \mathrm{S}$, al Oeste del páramo abrigado, desplazándose sobre el reborde oriental del altiplano hasta los $18^{\circ}$ Lat. Sur. $3^{\circ}$ ) Puna seca con 7 a 8 meses húmedos de 250 a $500 \mathrm{~mm}$ de lluvia, se extiende de la puna húmeda y sigue casi paralelamente hasta reemplazarla desde los $18^{\circ}$ lat. S en el muro oriental de la cordillera, aunque su limite austral llega $38^{\circ}$ de lat. sur, y $4^{\circ}$ ) Puna desértica con sólo 250 a 300 $\mathrm{mm}$ de lluvia en apenas 2 a 6 meses húmedos, ocupa el amplio espacio geográfico de las altas cimas que va desde los $17^{\circ}$ a $28^{\circ}$ lat. S en Chile y Argentina, limitando al Este con la puna seca. Acá no hay rios y excepcionalmente existen algunos salares (Fig. 5 y 6).

LAUER (1975 y 1979) desde el punto de vista hídrico sitúa a los páramos ecuatorianos en el intervalo de 9-12 meses húmedos. Sin embargo, estas regiones poseen un período débil de lluvias 


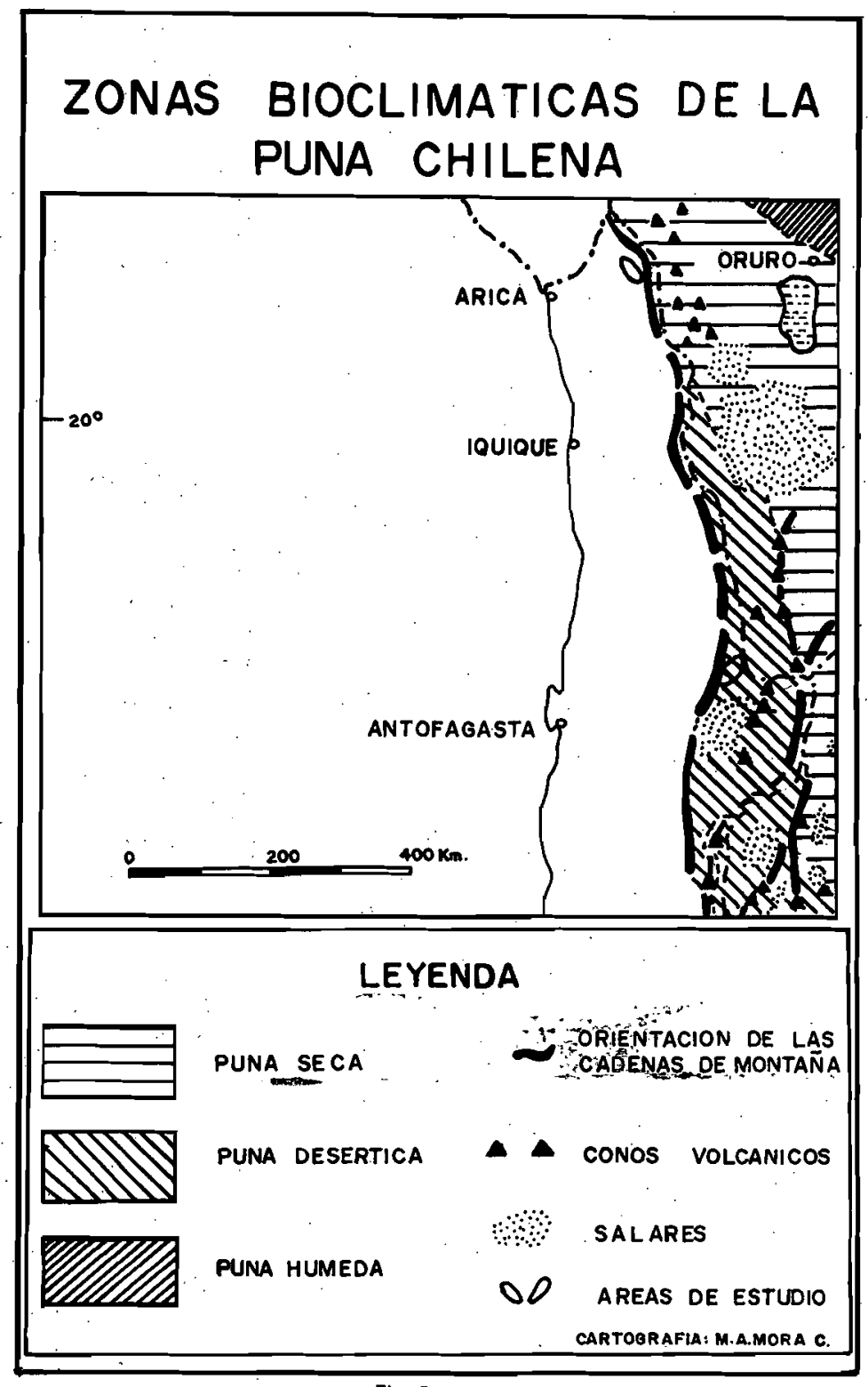

Fig. 5

entre 4 a 5 meses particularmente en la cordillera occidental. Durante estos meses las nieblas o la cubierta nubosa que se estaciona en la cordillera ecuatoriana se mantiene en los pisos inferiores correspondientes a la formación de la "ceja andina" (bosque de transición hacia el páramo) observándose así a menudo un tiempo asoleado y relativamente seco en los superiores, xerofitismo el cual no es debido a un factor térmico. En conclusión la región fitoecológica del páramo se restringe a la región húmeda de los Andes ecuatorianos especialmente en la región central de la cordillera oriental donde la precipitación anual supera los $500 \mathrm{~mm}$, además del aporte hídrico de las constantes horas de nieblas.

\section{LOS PRINCIPALES CARACTERES DE LA VEGETACION}

Los páramos del Ecuador tienen su distribución altitudinal preferentemente desde alrededor los $3.000 \mathrm{~m}$ en las cordilleras occidental $y$ oriental del pais, adquiriendo a su vez su mayor representa- 


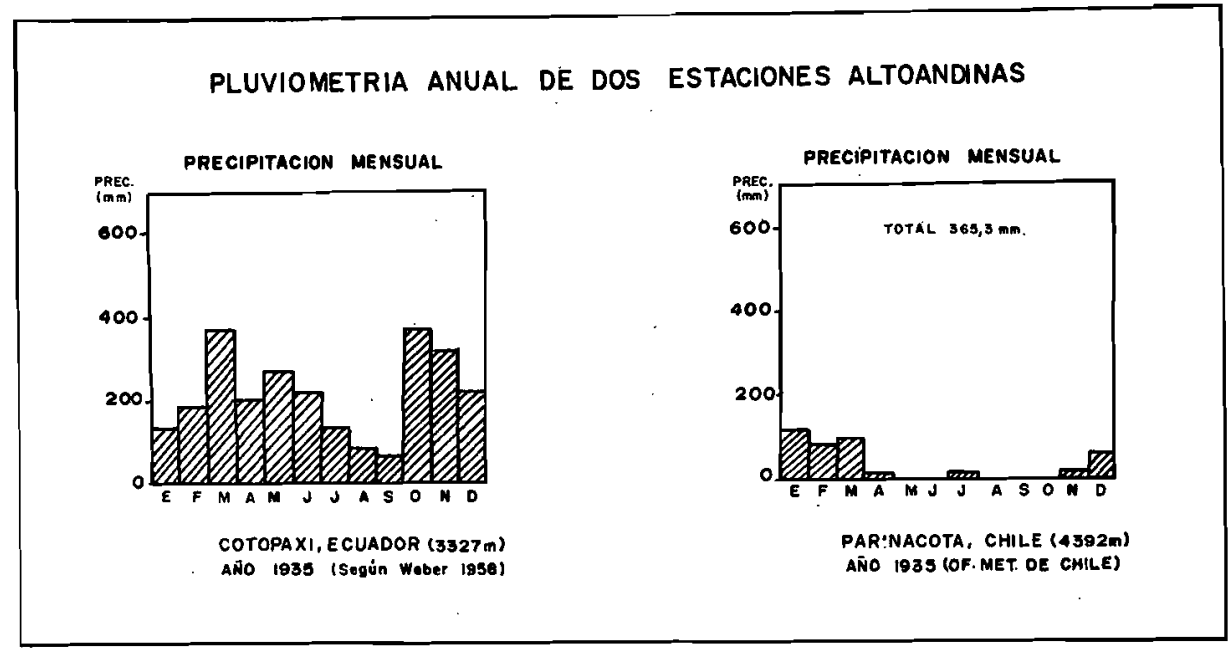

Fig. 6

tividad y variedad en la región central de esta última. Una cadena de conos volcánicos (Illiniza, Cayambe, Cotopaxi, Chimborazo, Rumiñahui) cobija a menudo los ambientes vegetales altoandinos. Bajo los $3.000 \mathrm{~m}$ y hasta alrededor de los $2.400 \mathrm{~m}$ existe una amplia faja húmeda caracterizada por un bosque mixto altomontano conocido como "ceja andina" o ceja de montaña y que para muchos autores constituiría un gran ecotono entre el bosque cerrado montano y el páramo (Werer 1963 y 1969; Troll 1968 y 1969). Según Harling (1978) se identifican tres ecosistemas páramo en las cordilleras ecuatorianas: a) El páramo graminoso situado entre los 3.400 y $4.000 \mathrm{~m}$ con dominancia de hierbas y arbustos, entre los que destacan especies de Ranunculus, Lupinus, Gentiana y pequeños arbustos de Baccharis, Chuquiraga e Hypochoeris. El género Espeletia, prácticamente casi hoy dia ha desaparecido de estos ambientes. b) El páramo arbustivo bajo y de plantas acojinadas se sitúa a continuación entre los 4.000 y $4.500 \mathrm{~m}$. Pueden encontrarse aqui pequeños árboles de Polylepis lanuginosa $(4.200-4.300 \mathrm{~m})$ y las hierbas y plantas arrosetadas se desarrollan un tanto dispersas. Son importantes las compuestas (Baccharis, Diplostephium rupestre, Chuquiraga jussieu, etc.), las Ericáceas, Juncáceas y Plantagináceas y el género Culcitium entre otros. Las plantas en roseta más representativas corresponden a las Umbeliferas: Azorella pedunculata, $A$. aretioides, $A$. corymbosa. c) Los páramos desérticos generalmente comienzan alrededor de los $440 \mathrm{~m}$ y se extienden hasta el límite de las nieves eternas. Aquí sólo se encuentran manchas muy espaciadas de plantas grasas xerofiticas, algunas pocas hierbas, arbustitos rampantes, varios tipos de musgos y liquenes; todos los cuales comparten el espacio con grandes bloques y material rocoso. Entre las fanerógamas que ascienden a mayor altitud destacan Epheda americana, Poa cucullata, Nototriche pichinchensis, Senecio spp., Werneria rigida y Culcitium nivale, entre otras (Fig. 7). De acuerdo con los tipos de hábitats propuestos por Mann (1966), los páramos de HaRLing (1978) en general estarían dentro de los ambientes de páramo y de puna húmeda.

Los ecosistemas altiplánicos chilenos se desarrollan en la vertiente occidental andina, correspondiente a la puna en gran parte sobre sustratos de lavas volcánicas, ignimbritas y tobas cretácicas, terciarias $y$ cuaternarias intercaladas con sedimentos clásicos como areniscas y conglomerados. También los macizos más altos de estas regiones corresponden a conos volcánicos con alturas de más o menos los 6.000 m.s.n.m. (Parinacota, Pomerape, Guallatiri, Isluga, Licancabur, etc.) Según Agele (1981) el piso de formas periglaciales de la región está caracterizado por laderas planas, formas redondeadas, suelos estriados y terrazas de solifluxión, y en éstas la influencia de la erosión torrencial, a consecuencias de las lluvias del denominado "invierno boliviano", es muy inferior a la de los pisos andinos inferiores. Así los efectos de esta erosión hídrica no parecen afectar gravemente al tapiz vegeral. Según la tipología de ManN (1966) estos ambientes chilenos corresponden a la denominada puna seca y desértica.

En los ecosistemas puneños chilenos la estructuración de los pisos vegetales es totalmente distinta de aquella de la cordillera ecuatoriana como se observa por ejemplo a la latitud de la ciudad de Arica (Fig. 8). Previo a los ecosistemas de la puna, existe un piso subandino prepuneño situado entre los 1.600 a $2.800 \mathrm{~m}$ caracterizado principalmente por una vegetación desértica de plantas espinosas y de cactáceas. En la latitud $15^{\circ} \mathrm{S}$ destaca el longevo "cactus candelabro" 


\section{LOS TIPOS DE PARAMOS EN ECUADOR}

$0^{\circ}$

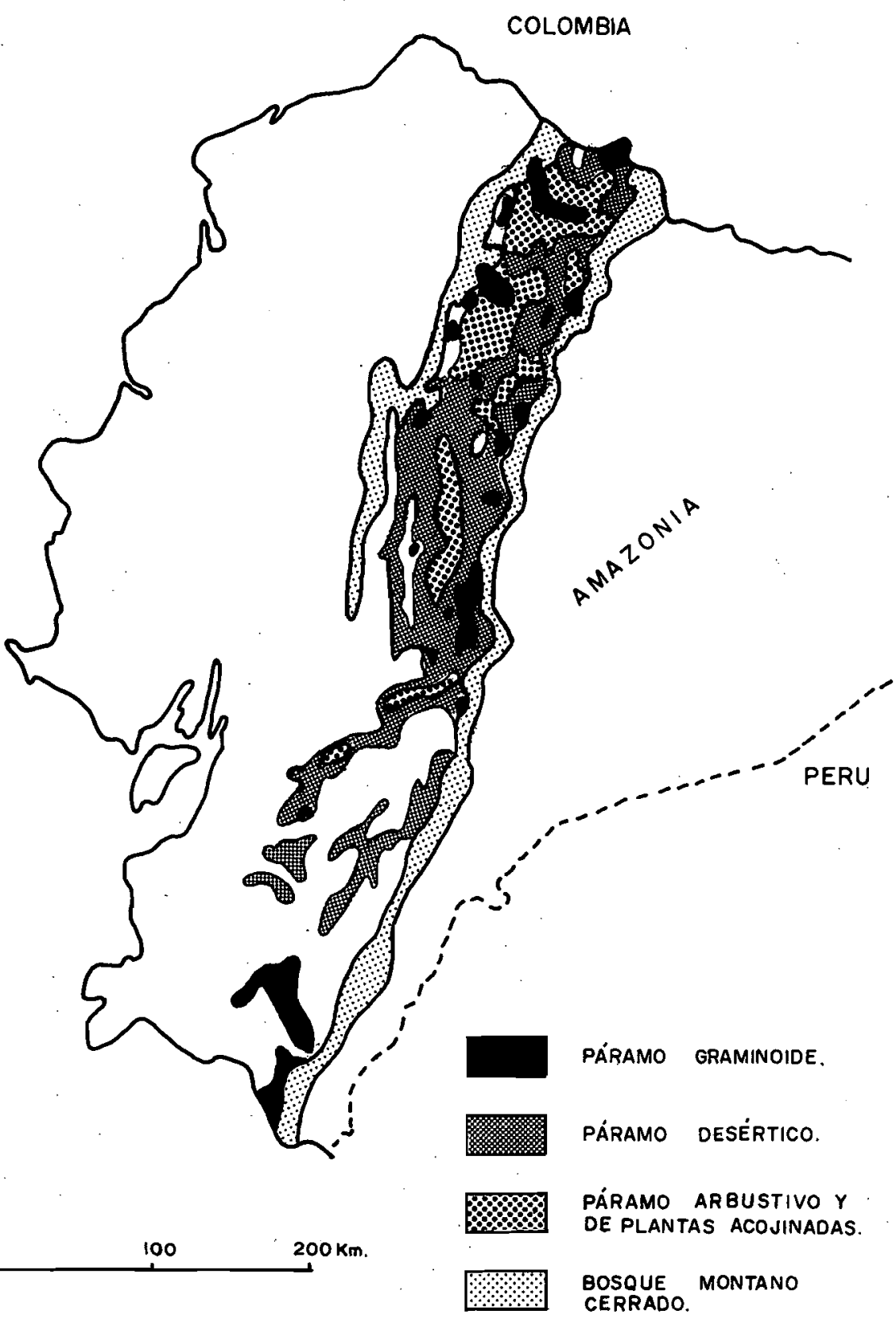

CARTOGRAFIA: MAM MORA.C. 
(Browingia cande/aris) en los ambientes interiores a $2.200 \mathrm{~m}$ y luego aparecen poco a poco especies arbustivas como Coldenia atacamensis, Acantholippia deserticola, Baccharis sp., Adesmia sp., Senecio sp.

Entre los 3.400 y $4.600 \mathrm{~m}$ por los planos y laderas de las montañas andinas se extiende el típico ambiente puneño. La vegetación está formada principalmente por el tolar constituido por arbustos espaciados de alrededor de 60 a $80 \mathrm{~cm}$ de altura (Fabiana densa, Baccharis tola, 8 . incarum), acompañados de diminutas plantas herbáceas que se desarrollan únicamente durante la estación de las lluvias. Hay aqui algunos géneros endémicos de la provincia puneña: Parastrephia, Lampaya, Chilotrichiops, Oreocerus, etc. Sobre los 4.000 metros y constituyendo a menudo ecotonos muy marcados con el tolar aparece el "pajonal", formación estépica de gramineas en champas la cual suele presentar dos estadios: en suelos arenosos húmedos (Ephedra breana, Werneria glaberrimma, Festuca sp., Pennisetum sp.) y en suelos húmedos y salobres (Festuca orthophylla, F. scirpifolia, Poa sp.). En suelos poco permeables y constituyendo las turbas o vegas andinas de los bofedales encontramos especies de Oxychloe andina, Festuca scirphifolia y Carex $s p$. Más arriba de los 4.300 o $4.400 \mathrm{~m}$ la vegetación estépica se interrumpe con frecuencia por áreas rocosas donde se desarrollan formaciones de Azorella compacta y de otras especies en cojines o placas.

Al interior de los sistemas andinos de la I $^{\mathrm{a}}$ Región chilena en forma espaciada y en las proximidades de quebradas y sectores de abrupta pendiente y sustrato rocoso, hay bosquecillos de "queñoa" (Polylepis tarapacana) que representa al único árbol que crece en estas alturas.

PERFIL BIOgeOgRAFICO A LA LATITUd DE LA CIUDAD DE ARICA

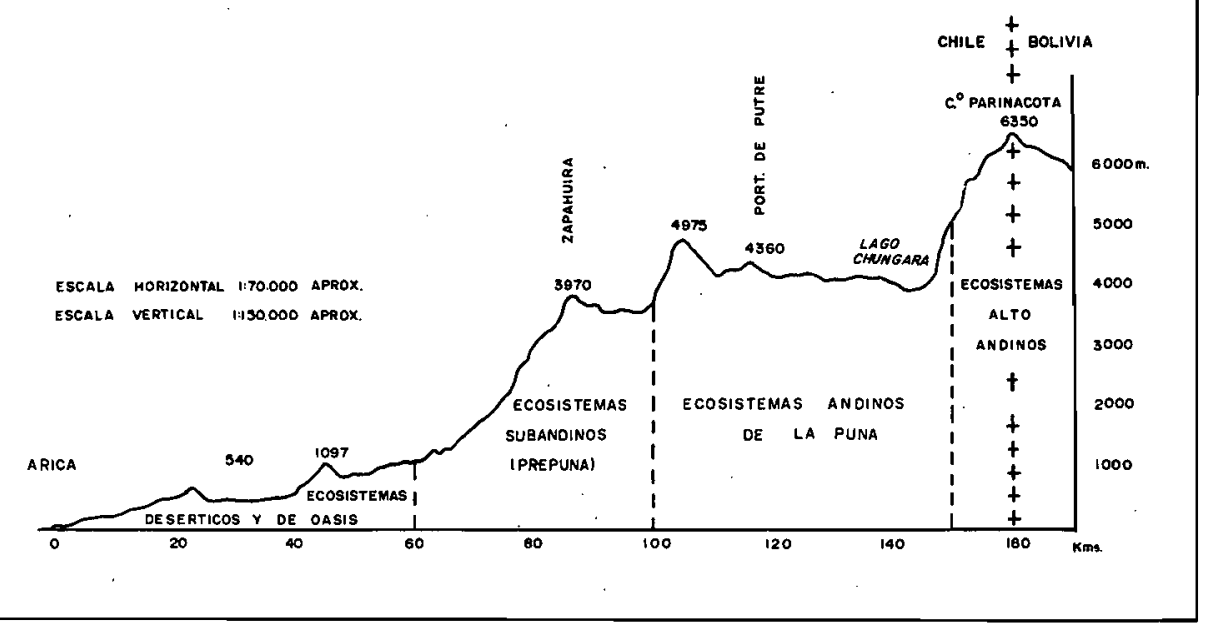

Fig. 8

\section{DISCUSION}

En las regiones altoandinas faltan casi por completo los árboles, predominando arbustos bajos con frecuencia rastreros o pulvinados, y las matas perennes. De acuerdo con el sistema de RAUNKIAER Y considerando preferentemente a las especies representativas que observamos, las formas biológicas de la puna y el páramo las hemos ordenado siguiendo el criterio de A. Cabrera (1968).

1. Microfanerofitas: Árboles de pequeña altura. En la puna chilena solo existe Polylepis tarapacana. En el páramo ecuatoriano estudiado encontramos Polylepis lanuginosa.

2. Nanofanerofitas. Arbustos bajos y observándose varios típos:

- Arbustos con ramas débiles y hojas pequeñas como Fabiana bryoides, Fabiana densa y Satureja parvifolia en la puna. En el páramo: Fabiana viscosa, Baccharis boliviensis y $B$. odorata. 
- Arbustos con hojas escamiformes muy apretadas como Paratrephia quadrangularis en la puna.

- Arbustos con hojas espiniformis como Chuquiraga kuschelli y Ch. spinosa en la puna. En tanto que en el páramo encontramos Chuquiraga insignis y Erigeron pinnatus entre otras.

- Arbustos de ramas espiniformes como Adesmia horrida, A. atacamensis y Nardophy/um sp. en la puna, y en el páramo Pernettya postrata.

- Arbustos con ramas dimorfas (con hojas espiniformes y ramas cortas de hojas pequeñas). En la puna destacan Junellia seriphioides, Fabiana bryoides y Nasauvia sp.

- arbustos áfilos como Ephedra breana y Fabiana denudata en la puna chilena; en tanto que en páramo ecuatoriano encontramos a Ephedra rupestris y $E$. americana.

3. Caméfitas. Plantas leñosas y sufruticosas con yemas de renuevo unos pocos cms por encima del suelo.

- Entre las sufruticosas encontramos en el páramo Lupinus microphyllus, Lupinus smithianus; según comunicación del Dr. Baslev.

- Caméfitos pulvinados, de ramas muy apretadas formando cojines radiales. En la puna chilena tenemos a Pycnophyllum bryoides. En el páramo destacan Azorella pedunculata $y$ Azorella sp.

- Caméfitas en placas con ramas subterráneas y formando placas compactas a ras del suelo. Azorella sp. y Adesmia sp. son importantes en la puna chilena; en tanto que en el páramo lo son Azorella aretioides, A. corymbosa y Plantago rigida.

- Arbustos rastreros con yemas casi a nivel del suelo como Parastrephia quadrangularis en la puna y Senecio microdon y $S$. cosmosus en el páramo.

4. Hemicriptófitas. Plantas herbáceas perennes con yemas de renuevo al nivel del suelo.

- Hemicriptófitas graminiformis incluyendo la mayor parte de las gramineas, ciperáceas y juncáceas. Destacan en la puna chilena Stipa ichu, S. venustra, S. frigida, Festuca ortophylla, F. chysophylla y Werneria glaberrimia, Distichlis spicata, Psila hirsuta. En el páramo encontramos Cortaderia nitida, Distichlis tolimensis, Festuca myrus, Werneria linearis, W. nubigens y también Stipa ichu.

- Hemicriptofitas arrosetadas como Plantago linearis y $P$. nubigena en el páramo ecuatoriano.

5. Heliófitas que poseen yemas de renuevo bajo un suelo inundado. Encontramos aquí a Oxcyloe andina en la puna chilena y a Luzula recemosa en el páramo.

6. Suculentas. Plantas grasas sin hojas como las cactáceas. En la puna chilena destacarian

Opunthia sp. y Cereus atacamensis (Holeanthocereus chilensis).

Es muy difícil establecer cuáles adaptaciones de las plantas se deben a una larga selección natural de formas aptas y cuáles han sido inducidas directamente por el ambiente, recordando además que son muy escasos todavía los trabajos sobre la ecologia de las plantas tropoandinas.

Los factores ambientales de la puna y del páramo, no influyen de la misma manera en la vida de las plantas de unos y otros ecosistemas. Señalamos a continuación cómo se presentan globalmente los factores básicos en estos dos grandes ambientes andinos (Cuadro 1).

Como se deduce del cuadro comparativo anterior, la acción de los mismos factores ambientales en ambos ecosistemas genera variaciones importantes en los tipos vegetales, en su evolución y sobre su composición florística a nivel de especies. A macroescala tales influencias de los factores ecológicos son igualmente relevantes aunque no tan contrastantes, como lo observamos en tres macizos considerandos en el Cuadro 2, considerando áreas en estos sistemas cordilieranos. Por otra parte, es evidente que la acción de factores como la latitud, la altitud y el clima también inciden en la estructuración de formaciones vegetales tipo en la puna y en el páramo como se observa en el Cuadro 3.

El número de muestreos realizados por nosotros en los sectores estudiados no es aún suficiente para determinar el área de distribución espacial precisa de las especies más representativas de la puna y el páramo. No obstante, procuramos realizar los censos en gradientes altimétricas similares con un número de muestras relevantes y considerando las formas biológicas representativas de los distintos ambientes (Cuadro 4 y Fig. 9).

A pesar del número todavía poco representativo de los muestreos y censos realizados, ellos nos han permitido conocer un poco más de la ecología de estos ambientes y de algunas de sus especies; sobre todo cuando encontramos representantes de géneros y familias comunes en estos ecosistemas. Particularmente interesante aún es el caso de plantas que tienen una gran distribución latitudinal altoandina como sucede por ejemplo con Stipa ichu y Azorella compacta las cuales son muy comunes a varias regiones de los Andes.

Las formas de vida predominantes en estos sistemas son los arbustos y hierbas quienes muestran un desarrollo bastante compacto y estratificado en el páramo ecuatoriano. En el volcán 
Cuadro 1: Sintesls de la acción de los factores ecológlcos en la Puna y el Dáramo

\begin{tabular}{|c|c|}
\hline PUNA & PARAMO \\
\hline $\begin{array}{l}\text { - Déficit de agua durante la mayor parte del } \\
\text { año. }\end{array}$ & - Suficiente humedad a lo largo del año. \\
\hline $\begin{array}{l}\text { - Irregularidad en las precipitaciones y bajo } \\
\text { monto anual. }\end{array}$ & $\begin{array}{l}\text { - Mayor regularidad de precipitaciones y alto } \\
\text { monto anual. }\end{array}$ \\
\hline - Escasa o nula nubosidad. & — Alta nubosidad. \\
\hline - Humedad atmosférica muy baja. & - Alta humedad atmosférica. \\
\hline - Gran radiación solar directa. & - Moderada radiación y a veces casi nula. \\
\hline $\begin{array}{l}\text { - Temperaturas nocturnas inferiores a cero } \\
\text { grado durante todo el año. }\end{array}$ & $\begin{array}{l}\text { - } 9,5 \text { a } 10 \text { meses con temperaturas nocturnas } \\
\text { inferiores a } 0^{\circ} \mathrm{C} \text {. }\end{array}$ \\
\hline $\begin{array}{l}\text { - Amplia variación de la temperatura durante } \\
\text { el día. }\end{array}$ & $\begin{array}{l}\text { - Variación moderada de la temperatura du- } \\
\text { rante el dia. }\end{array}$ \\
\hline - Presencia frecuente del viento. & $\begin{array}{l}\text { - Presencia moderada de la acción del viento } \\
\text { excepto en sectores muy altos y abiertos. }\end{array}$ \\
\hline $\begin{array}{l}\text { - Rol moderado del factor exposición de ver- } \\
\text { tientes. }\end{array}$ & $\begin{array}{l}\text { - Gran importancia del factor exposición de } \\
\text { vertientes sobre las precipitaciones y el } \\
\text { viento. }\end{array}$ \\
\hline - Suelos muy sueltos y esqueléticos. & - Suelos moderadamente fértiles. \\
\hline - Abundancia de sales solubles en suelos. & - Escasas sales solubles. \\
\hline - No hay quema de vegetación. & $\begin{array}{l}\text { - Quema del páramo para renovar las calidad } \\
\text { de los pastos. }\end{array}$ \\
\hline - Actividad pastoril del hombre puneño. & $\begin{array}{l}\text { - Actividad pastoril y agraria de subsistencia } \\
\text { del habitante del páramo. }\end{array}$ \\
\hline
\end{tabular}

Cuadro 2: Sintesis a macroescala de los factores ecologicos básicos que caracterizan a áreas representativas de las zonas de estudio

\begin{tabular}{|c|c|c|c|c|}
\hline Sector & $\begin{array}{l}\text { Cotopaxi: } \\
\text { Vertiente } \\
\text { Occidental }\end{array}$ & $\begin{array}{c}\text { Cotopaxi: } \\
\text { Vertiente NE }\end{array}$ & Parinacota & Guallatiri \\
\hline Vegetación & Matorral-Pastizal & $\begin{array}{c}\text { Pradera gra- } \\
\text { minal } \\
\text { (páramo) }\end{array}$ & $\begin{array}{l}\text { Tolar-Pajonal } \\
\text { (bofedal) }\end{array}$ & $\begin{array}{c}\text { Pajonal-Llaretal } \\
\text { (queñoai) }\end{array}$ \\
\hline Altitud & 3860-3950 s.n.m. & $3950-4300$ & $3950-4600$ & $4000-4800$ \\
\hline Suelo & E $\underset{\text { Dystrandept }}{n} \mathrm{i}$ - & $\begin{array}{c}\text { Dystic cryan } \\
\text { dept }\end{array}$ & $\begin{array}{l}\text { Inceptisold lí- } \\
\text { ticos }\end{array}$ & Inceptisold vitrics \\
\hline Pendiente & $5 \%-<70 \%$ & $50 \% \cdot>70 \%$ & $10 \%->40 \%$ & $50 \%-75 \%$ \\
\hline $\begin{array}{l}\text { Temperaturas } \\
\text { medias aproxi- } \\
\text { madas }\end{array}$ & $6,8^{\circ} \mathrm{C}-5,2^{\circ} \mathrm{C}$ & $2,9^{\circ}-5^{\circ} \mathrm{C}$ & $2,5^{\circ}-6,0^{\circ} \mathrm{C}$ & $7,0^{\circ} \mathrm{C}$ \\
\hline Precipitación & $500-1000 \mathrm{~mm}$ & $500 \mathrm{~mm}$ & $280-300 \mathrm{~mm}$ & $<200 \mathrm{~mm}$ \\
\hline Acción humana & $\begin{array}{l}\text { Quemas de pas- } \\
\text { tizal. } \\
\text { Leña-carboneo } \\
\text { Pastoreo } \\
\text { Turismo } \\
\text { Parque Nacional }\end{array}$ & $\begin{array}{l}\text { Obras de in- } \\
\text { fraestructura. } \\
\text { Turismo } \\
\text { Acumulación } \\
\text { de deshechos }\end{array}$ & $\begin{array}{l}\text { Obras de in- } \\
\text { fraestructura. } \\
\text { Turismo: Par- } \\
\text { que Nacional } \\
\text { Libre pastoreo }\end{array}$ & $\begin{array}{l}\text { Libre pastoreo } \\
\text { Extracción de } \\
\text { leña } \\
\text { Explotación de } \\
\text { salares. }\end{array}$ \\
\hline
\end{tabular}

* Datos climáticos: para Chile, Weischet 1970 y Oficina Meteorológica de Chile y para Ecuador, Oficina Meteorológica del Ecuador. 
Cuadro 3: Comparación de los tipos vegetales del páramo y la puna

\begin{tabular}{|c|c|c|c|c|c|}
\hline Vegetación Tipo & Latit. & $\begin{array}{l}\text { Pp. Anual } \\
\text { mm }\end{array}$ & Altitud & $\begin{array}{c}\text { Plantas } \\
\text { características }\end{array}$ & Fisonomía \\
\hline $\begin{array}{l}\text { Bosque andino de neblina } \\
\text { páramo inf. } \\
\text { Tolar } \\
\text { prepuna }\end{array}$ & $\begin{array}{l}0-3,3^{\circ} \mathrm{S} \\
18-23^{\circ} \mathrm{S}\end{array}$ & $\begin{array}{l}+2000 \\
20-60\end{array}$ & $\begin{array}{l}3000 \mathrm{a} \\
3400 \mathrm{~m} \\
3000 \mathrm{a} \\
3800 \mathrm{~m}\end{array}$ & $\begin{array}{l}\text { Polylepis/Esca- } \\
\quad \text { llonia } \\
\text { Baccharis/Fa- } \\
\text { b ian a / Ades- } \\
\text { mia/Ephedra }\end{array}$ & $\begin{array}{l}\text { Bosque bajo 3-6 } \\
\mathrm{m} \\
\mathrm{M} \text { a } \mathrm{t} \text { o } \mathrm{r} \mathrm{r} \text { a } 1 \\
\text { abierto } \\
0,65-1 \mathrm{~m}\end{array}$ \\
\hline $\begin{array}{l}\text { Páramo húmedo } \\
\text { páramo }\end{array}$ & $0-2,5^{\circ} \mathrm{S}$ & $1500-2000$ & $\begin{array}{l}3400 \mathrm{a} \\
4000 \mathrm{~m}\end{array}$ & Stipa/Festuca & $\begin{array}{c}\text { Pastizal cerrado } \\
60-150 \mathrm{~cm}\end{array}$ \\
\hline $\begin{array}{l}\text { Coironal-pajonal } \\
\text { puna }\end{array}$ & $18-21^{\circ} \mathrm{S}$ & $80-120$ & $\begin{array}{l}3800 \mathrm{a} \\
4600 \mathrm{~m}\end{array}$ & $\begin{array}{c}\text { Festuca/Stipa } \\
\text { Distichlis }\end{array}$ & $\begin{array}{l}\text { Estepa de hier- } \\
\text { bas y grami- } \\
\text { neas: } \\
\quad 0,40-0,80 \mathrm{~m}\end{array}$ \\
\hline $\begin{array}{l}\text { Bofedal } \\
\text { vega andina, turba. }\end{array}$ & $18-20^{\circ} \mathrm{S}$ & 200 & $\begin{array}{l}4000 \mathrm{a} \\
5000 \mathrm{~m}\end{array}$ & $\begin{array}{l}\text { Oxchyloe/Carex } \\
\text { Festuca/Patosia }\end{array}$ & $\begin{array}{c}\text { puna húmeda o } \\
\text { com un ida d } \\
\text { edáfica: } 0,20 \text { - } \\
0,40 \mathrm{~m}\end{array}$ \\
\hline $\begin{array}{l}\text { Páramo frio } \\
\text { pastizal altoandino } \\
\text { Veget. altoandina } \\
\text { llaretal }\end{array}$ & $\begin{array}{l}0.1,30^{\circ} \mathrm{S} \\
18-19,5^{\circ}\end{array}$ & $\begin{array}{l}500-1000 \\
>100\end{array}$ & $\begin{array}{l}4000 \mathrm{a} \\
4800 \mathrm{~m} \\
4600 \mathrm{a} \\
5300 \mathrm{~m}\end{array}$ & $\begin{array}{l}\text { Pernettya/Ep- } \\
\text { hedra/Calceo- } \\
\text { laria } \\
\text { Senecio/Mulli- } \\
\text { num/Azorella/ } \\
\text { Laretia }\end{array}$ & $\begin{array}{c}\text { Pradera alto an- } \\
\text { dina } \\
0,20-0,40 \mathrm{~m} \\
\text { Comunidades } \\
\text { en cojin: } \\
2-10 \mathrm{cms} \text {. }\end{array}$ \\
\hline
\end{tabular}

Cuadro 4: Ejemplo de una tabla resumen de líneas de extensión de muestras a altitudes $y$ vertientes comparables

\begin{tabular}{|c|c|c|c|c|c|c|c|c|c|}
\hline \multirow{4}{*}{$\begin{array}{c}\text { Altitud } \\
\text { m.s.n.m. }\end{array}$} & \multicolumn{3}{|c|}{ Ecosistema: } & \multicolumn{6}{|c|}{ PARAMO } \\
\hline & \multicolumn{3}{|c|}{ Sector W. Salar de Surire } & \multicolumn{2}{|c|}{ Sector Vn. Cotopaxi } & \multirow{3}{*}{$\begin{array}{l}\text { Total ms. } \\
\text { mues- } \\
\text { treados }\end{array}$} & \multicolumn{3}{|c|}{ Sector Vn. Rumiñahui } \\
\hline & \multicolumn{2}{|c|}{$\mathrm{N}^{0}$ de lineas } & \multirow{2}{*}{$\begin{array}{l}\text { Total ms. } \\
\text { mues- } \\
\text { treados }\end{array}$} & \multicolumn{2}{|c|}{$\mathrm{N}^{\circ}$ de líneas } & & \multicolumn{2}{|c|}{$N^{\circ}$ de líneas } & \multirow{2}{*}{$\begin{array}{c}\text { Total ms } \\
\text { mues- } \\
\text { treados }\end{array}$} \\
\hline & Arbustos & Hierbas & & Arbustos & Hierbas & & Arbustos & Hierbas & \\
\hline 3.900 & 1 & 5 & 30 & - & 3 & 15 & 3 & 3 & 45 \\
\hline 4.000 & - & - & 45 & 5 & 3 & 15 & 4 & 4 & 60 \\
\hline 4.100 & 1 & 3 & 45 & 3 & 5 & 55 & 4 & 4 & 60 \\
\hline 4.200 & - & 5 & 45 & - & 5 & 55 & 1 & 3 & 25 \\
\hline 4.300 & 1 & 4 & 50 & - & 5 & 25 & 4 & 4 & 60 \\
\hline 4.400 & 2 & 3 & 45 & - & 5 & 25 & - & 2 & 20 \\
\hline 4.500 & - & 3 & 45 & - & 5 & 25 & - & - & - \\
\hline \multirow[t]{2}{*}{ Totales } & 5 & 23 & & 8 & 31 & & 16 & 20 & \\
\hline & Individuo & s: 28 & 305 & Individuo & s: 39 & 215 & Individuo & s: 34 & 270 \\
\hline
\end{tabular}

Muestreos = Julio de 1980

Muestreos $=$ Agosto de 1982

Cotopaxi el estrato herbáceo adquiere una talla promedio de $30 \mathrm{cms}$ de alto, aunque las plantas con mayor abundancia y frecuencia relativa corresponden a individuos que no sobrepasan los 8 cms de alto en muestreos efectuados por nosotros a los 4.200 metros en laderas occidentales de este volcán. A su vez el I.V.I. baja levemente con el ascenso altitudinal para las especies representativas (Cuadro 5 y Fig. 10).

En una síntesis de muestreos del estrato arbustivo de este mismo volcán estrato y realizado a 


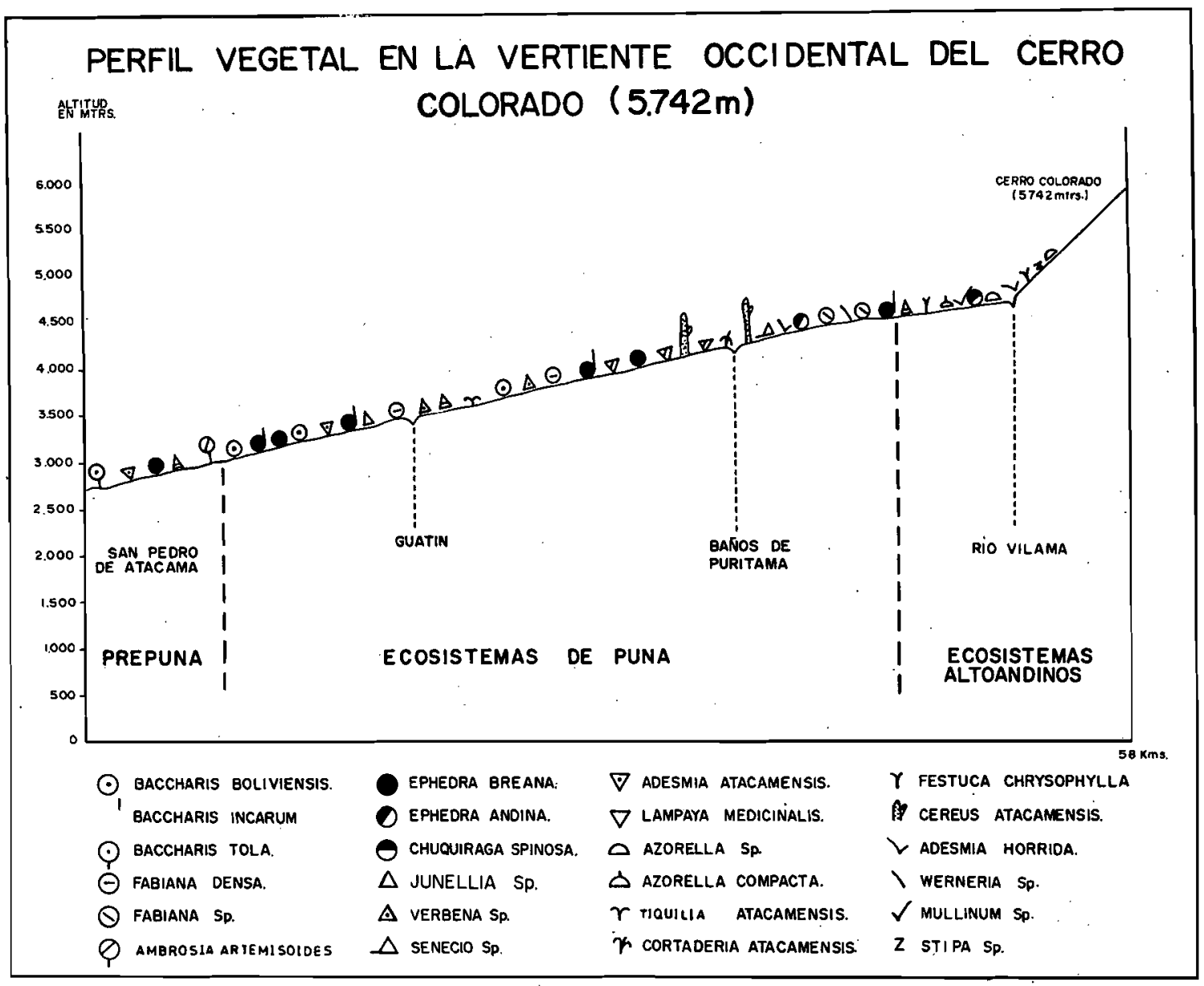

Fig. 9

los 4.000 m.s.n.m., observamos que la fisonomia de las plantas aquí demuestran un mayor desarrollo altimétrico $-60 \mathrm{cms}$ de alto promedio- y el I.V.l. individual de las especies es mayor que el de los componentes del estrato herbáceo localizado 200 metros más arriba. Sin embargo llama la atención que es una hierba (Stipa ichu) y no un arbusto quien alcanza aquí los mayores porcentajes de abundancia, frecuencia y dominancia relativas en el área muestreada y por tanto adquiere un alto I.V.I. entre los 3.900 y $4.000 \mathrm{~m}$ en la vertiente noroccidental del Cotopaxi (Cuadro 6 y Fig. 11). Deducimos que una de las probables explicaciones de este hecho, es la función ecológica de esta especie caracterizada por ejemplo por la amplia distribución tanto altitudinal como latitudinal que posee esta gramínea en el reino floral andino. Por otra parte observamos que esta es una de las tantas plantas que forman parte de las amplias zonas de ecotonos que existen en el páramo ecuatoriano y cuyos gradientes altimétricos están muy deformados a causa sobre todo de la acción antrópica.

En los sectores de la puna chilena, el análisis de los datos nos entregó -por ejemplo en el área de Puripica-Vilama-Cerro Colorado- valores relativamente bajos del I.V.I. de las especies censadas en el estrato herbáceo, a excepción de las arbustivas, en una época determinada del año (Cuadro 7). Esperamos, en futuras campañas de terreno a efectuar en otra estación climática, poder confrontar nuevos análisis de censos con estos parámetros y arribar así a conclusiones un poco más definitivas. En esta misma área, el I.V.I. en relación a la distribución altitudinal de las especies arbustivas indicadoras, muestra un porcentaje relativamente homogéneo aunque bajo, para tres plantas representativas tanto de la puna como del piso altoandino: Festuca chrysophy/a, Werneria sp. y Baccharis incarum, demostraron una distribución porcentual de abundancia, frecuencia y dominancia relativas de un 20 a $30 \%$ entre los 3.700 y los -4.300 metros (Fig. 12). En la región montañosa del Salar de Surire en cambio, pudimos comprobar la existencia de un I.V.I. con 
un porcentaje más significativo para las especies indicadoras de la formación quienes aún encuentran un ambiente adecuado por sobre los 4.000 s.n.m. Notable es aqui observar, en algunas zonas rocosas y de abrupta pendiente, la presencia de Polylepis tarapacana el único árbol de la puna y los altos Andes (Fig. 13).

Cuadro 5: Resumen de Datos Sinecológlcos e índice de Valor de Importancia Sector: Cotopaxi Altitud: 4.200 m.s.n.m. Estrato: herbáceo Fecha: 6-VIII-82

\begin{tabular}{llccccc}
\hline ESPECIE & FAMILIA & $\begin{array}{c}\text { Altura cms } \\
\text { observada }\end{array}$ & $\begin{array}{c}\text { Abundancia } \\
\text { relativa \% }\end{array}$ & $\begin{array}{c}\text { Frecuencia } \\
\text { relativa \% }\end{array}$ & $\begin{array}{c}\text { Dominancia } \\
\text { relativa \% }\end{array}$ & $\begin{array}{c}\text { índice de } \\
\text { valor de l\% }\end{array}$ \\
\hline Plantago nubigena & Plantaginaceae & 1 & 37.50 & 2.08 & 61.73 & 33.80 \\
Stipa sp. & Graminae & 4 & 40.71 & 6.25 & 8.11 & 8.35 \\
Werneria nubigena & Compositae & 3 & 11.09 & 8.33 & 2.84 & 7.42 \\
Azorella pedunculata & Umbelliferae & 2 & 6.59 & 6.25 & 2.73 & 6.18 \\
Geranium multipartitum & Geraniaceae & 2 & 4.13 & 2.08 & 7.10 & 4.43 \\
Lupinus microphyllus & Leguminosae & 12 & 1.31 & 6.25 & 2.87 & 3.47 \\
Hipochaeris sesiflora & Compositae & 2 & 2.44 & 6.25 & 0.70 & 3.13 \\
Pernettya postrata & Ericaceae & 2 & 2.81 & 6.25 & 0.21 & 3.09 \\
Diplostephium sp. & Compositae & 3 & 3.0 & 6.25 & 2.91 & 3.90 \\
Chuquiraga insignis & Compositae & 62 & 1.12 & 4.16 & 3.32 & 2.86 \\
Alchemilla orbiculata & Rosaceae & 2 & 1.69 & 6.25 & 1.16 & 2.70 \\
Muehlenbeckia vulcanica Polygonaceae & 1 & 3.0 & 4.16 & 1.23 & 2.46 \\
Luzula racemosa & Juncaceae & 3 & 3.38 & 6.08 & 1.86 & 2.44 \\
Plantago linearis & Plantaginaceae & 3 & 4.32 & 4.08 & 0.88 & 2.44 \\
Sterocaulon speciosum & Cladionaceae & 2 & 1.31 & 4.16 & 0.64 & 2.93 \\
Halenia weddeliana & Gentianaceae & 2 & 1.31 & 4.16 & 0.21 & 1.89 \\
Gentianella cerastioides & Gentianaceae & 3 & 0.93 & 4.16 & 0.03 & 1.70 \\
Carex sp. & Cyperaceae & 2 & 0.56 & 4.16 & 0.01 & 1.57 \\
Gnaphalium spp. & Compositae & 2 & 1.12 & 2.08 & 1.14 & 1.44 \\
\hline
\end{tabular}

Cuadro 6: Tabla tipo para el Resumen de Datos Sinecológlcos e Índice de Valor de Importancia

Sector: Vn. Cotopaxi Altitud: 4.000 m.s.n.m. Estrato: arbustivo. Fecha: 6-VIII-1982

\begin{tabular}{llccccc}
\hline ESPECIE & FAMILIA & $\begin{array}{c}\text { Altura cms } \\
\text { observada }\end{array}$ & $\begin{array}{c}\text { Abundancia } \\
\text { relativa \% }\end{array}$ & $\begin{array}{c}\text { Frecuencia } \\
\text { relativa \% }\end{array}$ & $\begin{array}{c}\text { Dominancia } \\
\text { relativa \% }\end{array}$ & $\begin{array}{c}\text { indice de } \\
\text { valor de I }\end{array}$ \\
\hline Stipa ichu & Graminae & 56 & 59.15 & 21.7 & 63.43 & 48.09 \\
Valeriana microphylla & Valerianaceae & 60 & 14.08 & 17.03 & 9.05 & 13.47 \\
Chuquiraga insignis & Compositae & 100 & 8.45 & 13.04 & 16.42 & 12.63 \\
Gynoxis buxifolia & Compositae & 60 & 4.22 & 13.04 & 3.61 & 6.95 \\
Senecio ericaefolius & Compositae & 64 & 4.222 & 13.04 & 0.97 & 6.07 \\
Baccharis odorata & Compositae & 78 & 2.81 & 8.60 & 2.86 & 4.75 \\
Pernettya postrata & Ericaceae & 51 & 2.81 & 4.34 & 2.60 & 3.25 \\
Tafalla stenophylla & Compositae & 75 & 1.40 & 4.34 & 0.89 & 2.21 \\
Monnina sp. & Polygalaceae & 74 & 2.81 & 4.34 & 0.12 & 2.42 \\
\hline Total: 9 & \multicolumn{1}{c}{9} & & 100 & 100 & 100 & 100 \\
\hline
\end{tabular}

La anatomía y la especialización ecológica de las plantas de la puna y de los altos Andes, explican de modo general su amplia y a la vez variada distribución altimétrica en estos ambientes. Las caracteristicas adaptativas deben sin duda estar relacionadas con la obtención de agua, la conservación de la misma acumulándola o reduciendo la transpiración, la adecuación a suelos pobres y en pendientes aguzadas, la resistencia a temperaturas muy bajas y a veces a un intenso 


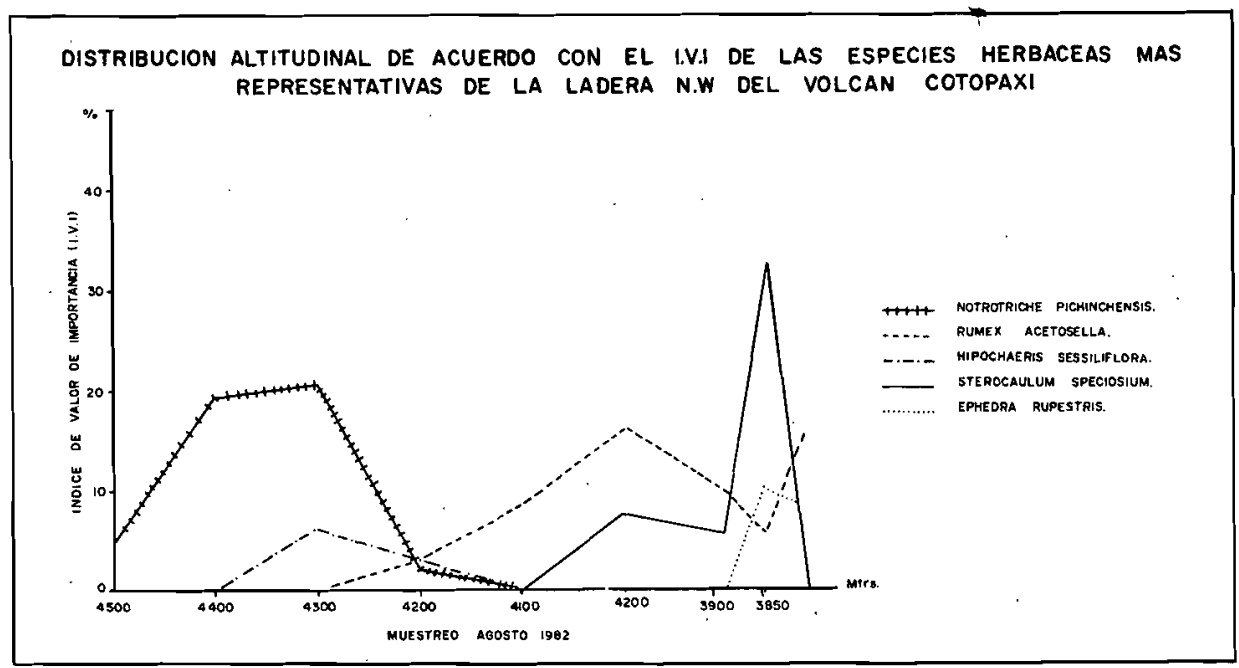

Fig. 10

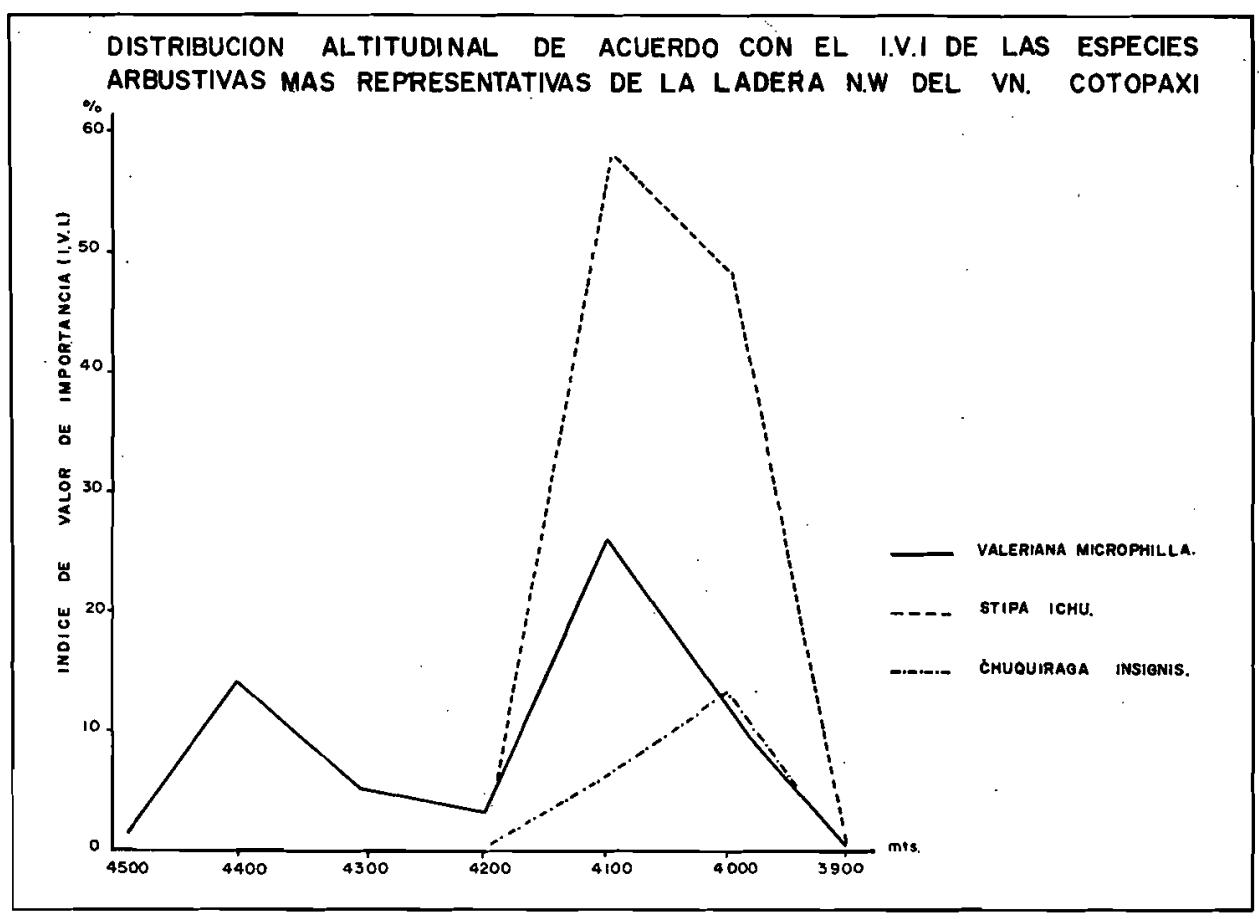

Fig. 11

viento. Sin embargo, es difícil establecer con qué factor adverso está relacionada una determinada estructura de la planta, a pesar que recientemente autores nacionales han ido publicando trabajos pioneros sobre estos aspectos.

La especialización de estos organismos vegetales ante ambientes aparentemente tan limitantes, se logra mediante funciones adaptativas de las raices, tallos $u$ hojas de estas plantas. Cabrera (1957-1971) cita por ejemplo el caso de fabiana densa la cual posee un tallo de unos 20 cms de alto en circunstancias que tiene raices de 2 metros de largo, mediante las cuales puede obtener agua de las capas inferiores del suelo; tallos crasos acumuladores de agua como ocurre con las cactáceasas y otras plantas, y formación de cojines o de placas por crecimiento muy denso de las ramas como sucede con Azorella compacta, Laretia compacta, Junellia sp. y Adesmia spp. Ello se ha considerado como una adaptación a la sequía y el viento. El rol de este último factor lo 
Cuadro 7: Tabla tipo para el Resumen de Datos Sinecológicos e Índice de Valor de Importancla

Sector: Puripica-Vilama (Cerro Colorado). Altitud: 4.100 metros. Estrato:

herbáceo. Fecha: 17 julio 1977

\begin{tabular}{llccccc}
\hline ESPECIE & FAMILIA & $\begin{array}{c}\text { Altura cms } \\
\text { observada }\end{array}$ & $\begin{array}{c}\text { Abundancia } \\
\text { relativa } \%\end{array}$ & $\begin{array}{c}\text { Frecuencia } \\
\text { relativa } \%\end{array}$ & $\begin{array}{c}\text { Dominancia } \\
\text { relativa \% }\end{array}$ & $\begin{array}{c}\text { indice } \\
\text { V.I. }\end{array}$ \\
\hline Baccharis incarum & Compositae & 23 & 19.0 & 10.0 & 59.15 & 26.71 \\
Fabiana densa & Solanaceae & 25 & 8.0 & 9.0 & 22.85 & 13.28 \\
Adesmia horrida & Papilonaceae & 15 & 13.0 & 9.8 & 9.20 & 10.40 \\
$\begin{array}{l}\text { Parastraphia quadrangu-Compositae } \\
\text { laris }\end{array}$ & 5 & 4.0 & 5.3 & 0.10 & 3.8 \\
Lampaya medicinalis & Verbenaceae & 20 & 10.0 & 9.6 & 1.5 & 6.83 \\
Festuca chrysophylla & Graminae & 29 & 12.0 & 8.8 & 0.3 & 6.36 \\
$\begin{array}{l}\text { Pycnophyllum bryoides } \\
\text { Senecio rosmarinus }\end{array}$ & Caryophyllaceae & 2 & 5.8 & 9.0 & 1.16 & 5.92 \\
Ephedra breana & Compositae & 5 & 5.0 & 9.0 & 1.46 & 5.15 \\
Werneria glaberrima & Compositae & 10 & 5.0 & 6.8 & 0.90 & 4.56 \\
Mullinum crassifolium & Umbelliferae & 10 & 7.0 & 6.5 & 0.69 & 5.96 \\
Azorella compacta & Umbelliferae & 2 & 4.0 & 6.27 & 1.2 & 4.11 \\
Junellia sp. & Verbenaceae & 10 & 1.2 & 2.27 & 0.08 & 1.09 \\
\hline Total & & & 100.0 & 100.0 & 100.0 & 100.0 \\
\hline
\end{tabular}

ha puesto recientemente en evidencia ENOLICHER (1982), para las plantas del páramo desértico del Ecuador.

La adaptación de las hojas también es extraordinariamente sorprendente. Ellas aparecen en un número reducido, pequeñas y coriáceas como en Psila boliviensis, Baccharis incarum, Fabiana densa y Junellia seriphioides (Cabrera 1971). Otras veces pueden encontrarse plantas con hojas carnosas, de bordes enroscados espiniformes y rigidas, lo cual les permite reducir la transpiración y de defensa contra los herbivoros, como puede ser el caso de Chuquiraga atacamensis, o poseer hojas escamiformes, densas y apretadas contra el tallo, el cual frecuentemente se halla cubierto de pelos lanosos, de manera que entre la hoja y el tallo se forma una cámara donde la humedad es mayor y los cambios de temperatura menos marcados. Este tipo de hojas se encontraría según CABRERA (1971) y VILLAGRÁN et. al., (1981) en Parastrephia quadrangularis y en Azorella compacta en nuestros ambientes puneños.
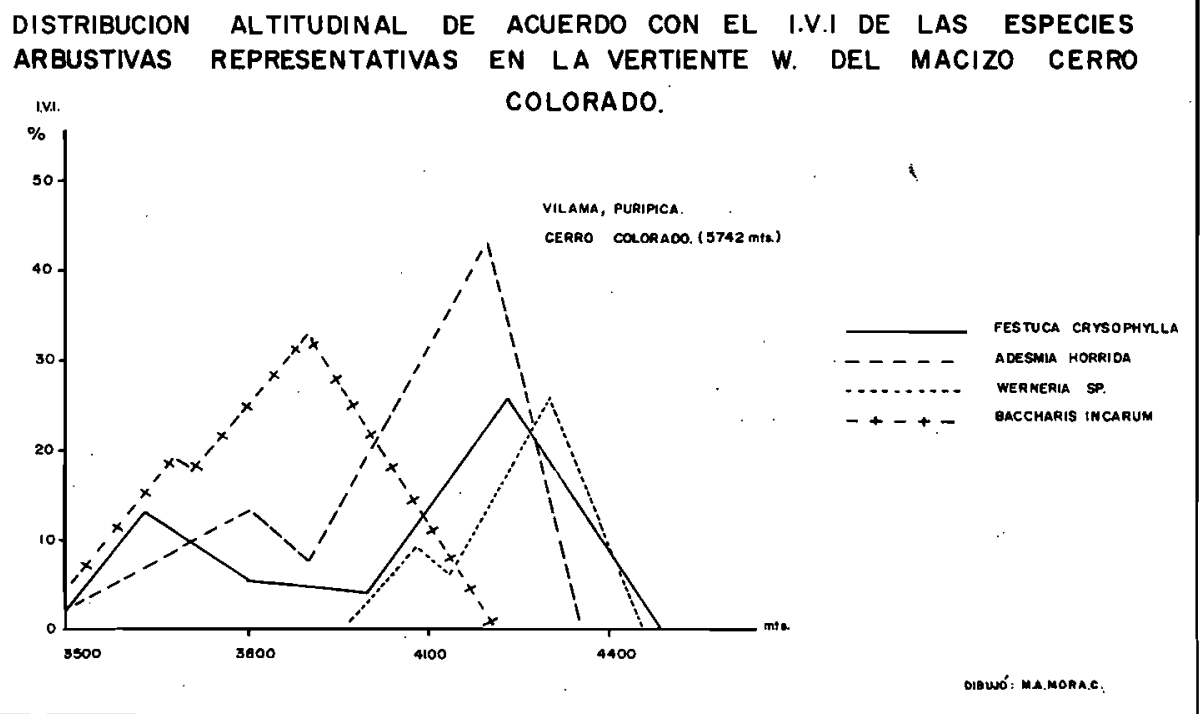

Fig. 12 


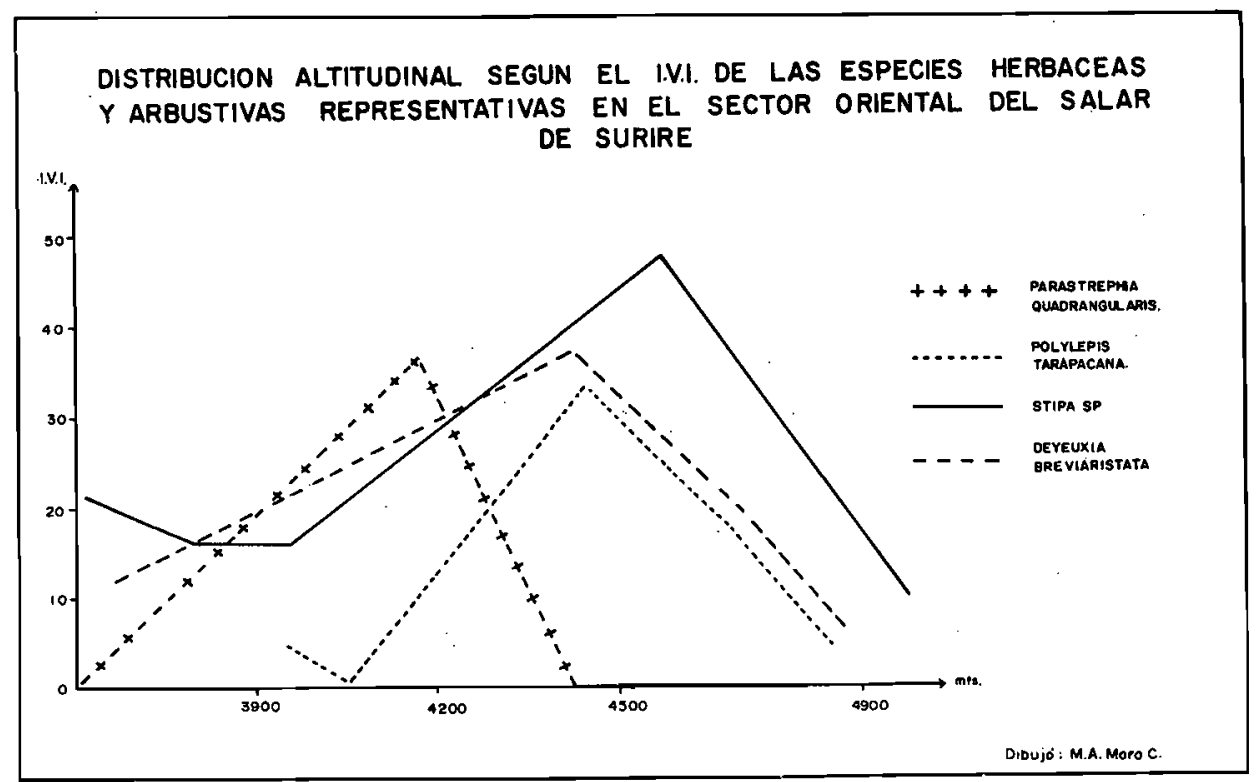

Fig. 13

\section{CONCLUSIONES}

Las conclusiones de este primer estudio comparativo en estos dos ambientes tropandinos, parecen claras aunque no son suficientemente precisas.

Resalta en primer término la diferenciación de tipos fisionómicos en la puna y en el páramo. Las formaciones vegetales se adaptan perfectamente a condiciones ecológicas propias de climas de altura, tanto en ambientes secos como húmedos. Luego, la flora de estos ecosistemas es distinta - con muy pocas excepciones- $y$ en ambos las especies desarrollan modos de vida singulares en relación con las características de sus biotopos.

En la puna y el páramo, es evidente la peculiar adaptación, de las plantas como comunidades o como individuos a las duras condiciones abióticas de sus respectivos medios ecológicos. Sin embargo las características particulares de estos procesos en cada especie, son aún muy desconocidas. Más lejano aún parece estar este conocimiento cuando comprobamos la escasez in situ de estaciones registradoras del clima y de datos del suelo de que adolecen la mayoría de los sistemas cordilleranos en el continente.

Se ha comprobado que es muy dificil manejar una tipologia inica para los diferentes ambientes del páramo. Numerosos autores han propuesto clasificaciones y, ni aun utilizando criterios similares, estas divisiones fitogeográficas y botánicas son plenamente coincidentes. Esto dificulta notablemente establecer rangos comparativos entre las formaciones vegetales de la puna y del páramo, las cuales - en una primera conclusión-podríamos decir que fitoecológicamente son distintos. Por otra parte en la puna chilena, se puede proponer divisiones más precisas de sus ambientes naturales probablemente, entre otras causas, debido a que en ellos se desarrollan caracteres ecológicos más estables, entre ellos la sequedad por ejemplo.

Fisionómicamente, las comunidades vegetales de los páramos constituyen agrupaciones más extensas y densas que aquéllas de la puna. Hemos visto que la frecuencia de arbustos es mayor en las cordilleras del Ecuador y que la talla media.de las especies arbustivas, sobrepasa los $50 \mathrm{cms}$ en el páramo, en tanto que llega sólo a unos $30 \mathrm{cms}$ en la puna. A su vez el índice de valor de importancia de las herbáceas, también es más representativo en los ambientes parameros que en los puneños.

A nivel de familia, las especies arbustivas de la puna sólo se repiten en una proporción reducida en los ambientes andinos del Ecuador; considerando que la mayoría de los arbustos del páramo poseen una distribución latitudinal muy vasta, desde Venezuela hasta el norte del Perú.

La constante actividad pastoril y agricola del hombre andino del páramo y de la puna dificultan todavía más la posibilidad de realizar estudios, dentro de un marco permanentemente natural de estos ecosistemas. No obstante debemos consignar que en la puna chilena, se 
desarrolla una relación hombre-ambiente más próxima a un equilibrio ecológico por cuanto aquí la presión humana es menor que en el páramo ecuatoriano.

\title{
AGRADECIMIENTOS
}

El autor agradece a la profesora Carolina Villagrán, de la Facultad de Ciencias Básicas, la minuciosa revisión y sugerencias al presente manuscrito.

\section{REFERENCIAS BIBLIOGRÁFICAS}

ABELE, G. 1981. Zonificación altitudinal morfológica e hídrica de la vertiente andina occidental en la región limítrofe chileno-peruana. R. Geogr. Norte Grande. 8: 3-36.

Baaun-Blanouet, J. 1964 Pflanzensoziologie. ( $3^{a}$. ed.) Springer V. Wienne.

Cabrera, A. 1957. La vegetación de la Puna Argentina. R. Invest. Agrícolas 11: 317-412.

Cabrera, A. 1968. Ecología Vegetal de la Puna. Colloqium Geogr. Universidad de Bonn. 9: 91-116.

Cabrera, A. 1968. Fitogeografía de la República Argentina. Bol. Soc. Argentina de Botánica. 14: 1-42.

CANFIELD, R.H. 1962. Sampling Ranges by the Line Interception Method. Plant cover Composition-Density Degree of Forage Use (reed.) Res. Rep.: 4 U.S.D.A. For serr. South-western For Range Exp.

CZAJKA, W. 1968. Los perfiles vegetales entre Alaska y Tierra del Fuego. Proc. UNESCO México "Symposium" Geoecology of the Mountainous regions of the Tropical Americas.

ENOLICHER, W. 1982. Ein Vergleich der anemometrischen Bedingungen in äquatorialen und nord hemisphärisch aussertropischen Hochgebirgen im Hinblick auf ihre ökologische Relevanz. Der Tages und Jahresgang der Wind geschwindigkeit den Hochanden von Ecuador. Freiburger Geogr. Hefte. 18: 157-168.

HARLING, G. 1978. The vegetation Types of Ecuador: a Brief Survey, In: Tropical Botany. K. Larsen and L. B. Holm Nielsen Eds. N. York 153-174.

LaUer, W. 1975. Von Wessen der Tropen. Steiner Verlag, Wiesbaden.

LaUer, W. 1979. La posición de los páramos en la estructura del paisaje de los Andes tropicales. El Medio Ambiente Páramo. Ed. M. L. Salgado-Labourian, México: 29-43.

MANN, G. 1966. Bases ecológicas de la explotación agropecuaria en América Latina. Depto. Asis. Cient. OEA WASHINGTON.

QuintaniLLA, V. 1976-77. Zonación altitudinal de la vegetación en el Norte árido chileno, a la latitud del Trópico de Capricornio. R. Norte Grande. 5: 17-39.

QuintaniLLA, V. 1983. Observaciones fitogeográficas en el páramo de la cordillera oriental del Ecuador. Bol. Inst. Francés de Est. Andinos. (1-2): 55-74.

TROLL, C. 1958. Zur Physiognomik der Tropengewäsche. Jahresber. d. Ges. von Freunden und Förderen der Rheinischen F., Universität. Bonn.

TrOLL, C. 1959. Die Tropischen Gebirge. Ihre dreidimensionale klimatische und pflanzengeographische Zonierung. Bon. Geogr. 25: 1-93.

VILLAGRÁN C. J. ARmesto \& K. ArRoyo. 1981. Vegetation in a high Andean transect between Turi and Cerro León in Northern Chile. Vegetation 48: 3-16.

WeBER, H. 1963: Uber die vegetation der hochandinen paramos. Jb. Ver. Schutz Alpenfl. und Tiere. München. WEBER, H. 1969. Zur natürlichen vegetations Gliederung von Südamerika.

WeISCHET, W. 1970. Chile, seine Länderkundiche, individualität und struktur. vol. I. Wissensch. buchgesellsch. Darmstadt.

\author{
APÉNDICE \\ LISTA DE ESPECIES REPRESENTATIVAS DE LOS ECOSISTEMAS \\ DE LA PUNA CHILENA ENCONTRADAS EN LAS ÁREAS DE ESTUDIO \\ (Vn. Parinacota, Vn. Gualatiri-sector Salar de Surire, Cerro Colorado).
}

FAMILIA
SOLANACEAE

COMPOSITAE

\section{ESPECIES}

Fabiana densa var. ramulosa

Fabiana denudata

Fabiana deserticola

Fabiana viscosa

Werneria glaberrima

Diplosteylium meyenü

Chuquiraga kuschelli

Baccharis boliviensis 
CHENOPODIACEAE

ROSACEAE

CRUCIFERAE

GRIMINAE

INULEAE

SENECIONEAE

GERANIACEAE

OXALIDACEAE

CARIOPHYLLACEAE

UMBELLIFERAE

CACTACEAE

CYPERACEAE

VERBENACEAE

ILLECEBRACEAE

MUTISIAEAE

EPHEDRACEAE

ASTEREAE

PAPILIONACEAE

BORAGINACEAE

LABIATAE

KRAMERIACEAE

FAMILIA

CARIOPHYLLACEAE

COMPOSITAE
Atriplex microphyllum

Polylepis tarapacana

Sisymbrium philippianum

Festuca orthophylla

Stipa leptostachya

Stipa venusta

Deyeuxia breviaristata

Festuca ortophylla

Cortaderia atacamensis

Distichlis sp.

Stipa ichu

Stipa sp.

Gnaphalium lacteum

Senecio phylloleptus

Senecio olivaceobracteatus

Senecio rosmarinus

Senecio candollü

Balbisia sp.

Oxalis aff. exigua

Pycnophyllum bryoides

Mulinum crassifolium

Azorella compacta

Laretia sp.

Moleanthocereus chilensis

Opuntia sp.

Oxychloe andina

Carex sp.

Lampaya medicinalis

Cardionema sp.

Chuquiraga spinosa

Ephedra breana

Ephedra sp.

Baccharis incarum

Diplostephium sp.

Adesmia horrida

Adesmia atacamensis

Coldenia atacamensis

Satureja parvifolia

Krameria iluca

LISTA DE ESPECIES COLECTADAS EN EL PÁRAMO.

Sector Volcánes Cotopaxi y Rumiñahui.

\section{ESPECIES}

Arenaria sp.

Baccharis caespitosa var. alpina

Baccharis odorata 


\begin{tabular}{|c|c|}
\hline & $\begin{array}{l}\text { Bidens humilis } \\
\text { Culcitium nivale } \\
\text { Chuquiraga insignis } \\
\text { Erigeron pinnatus } \\
\text { Hipochoeris sessiliflora } \\
\text { Gnaphalium sp. } \\
\text { Gynoxis buxifolia } \\
\text { Senecio ericaefolius } \\
\text { Senecio humboldtianus } \\
\text { Tafalla stenophylla } \\
\text { Werneria humilis } \\
\text { Werneria nubigena } \\
\text { Werneria linearis } \\
\text { Werneria sp. }\end{array}$ \\
\hline CRUCIFERAE & $\begin{array}{l}\text { Braya sp. } \\
\text { Draba ovobata Benth. } \\
\text { Draba sp. }\end{array}$ \\
\hline CYPERACEAE & Carex sp. \\
\hline EPHEDRACEAE & Ephedra rupestris \\
\hline ERICACEAE & $\begin{array}{l}\text { Perpettya postrata } \\
\text { Vaccinium aff. floribundum }\end{array}$ \\
\hline GENTIANACEAE & $\begin{array}{l}\text { Gentiana sedifolia } \\
\text { Gentianella cerastioides } \\
\text { Geranium purpureum }\end{array}$ \\
\hline GRAMINAE & $\begin{array}{l}\text { Festuca myurus } \mathrm{L} \text {. } \\
\text { Distichiis tolimensis } \\
\text { Cortaderia nitida } \\
\text { Bromus sp. } \\
\text { Festuca sp. } \\
\text { Stipa ichu }\end{array}$ \\
\hline JUNCACEAE & Luzula racemosa \\
\hline LEGUMINOCEAE & Lupinus microphyllus \\
\hline PLANTAGINACEAE & $\begin{array}{l}\text { Plantago linealis } \\
\text { Plantago nubigena }\end{array}$ \\
\hline POLYGONACEAE & $\begin{array}{l}\text { Muehlenbeckia vulcanica } \\
\text { Rumex acetosella }\end{array}$ \\
\hline LYCOPODICEAE & Lycopodium sp. \\
\hline ORCHIDACEAE & Orchis sp. \\
\hline ROSACEAE & $\begin{array}{l}\text { Alchemilla orbiculata } \\
\text { Lachemilla hirsuta } \\
\text { Polylepis lanuginosa }\end{array}$ \\
\hline RUBIACEAE & Galium sp. \\
\hline SCROPHULARIACEAE & $\begin{array}{l}\text { Bartsia brevifolia } \\
\text { Castilleja fissifolia } \\
\text { Siptorphia pichinchensis }\end{array}$ \\
\hline UMBELLIFERAE & $\begin{array}{l}\text { Azorella pedunculata } \\
\text { Azorella sp. } \\
\text { Eryngium sp. }\end{array}$ \\
\hline VALERIANACEAE & Valeriana microphylla \\
\hline ASTEREAE & Dipostephium sp. \\
\hline HELECHOS & $\begin{array}{l}\text { Grammitis moniliforme } \\
\text { Polypodium sp. } \\
\text { Polystichum sp. }\end{array}$ \\
\hline
\end{tabular}

